\title{
ICANN AND THE PROBLEM OF LEGITIMACY
}

\author{
JONATHAN WEINBERG $\dagger$
}

\begin{abstract}
Two years ago, an entity called the Internet Corporation for Assigned Names and Numbers (ICANN) was formed to take control of the Internet's infrastructure of domain name and IP address identifiers. Private parties formed ICANN at the behest of the U.S. government; the government is currently using its considerable resources to cement ICANN's authority over the domain name space. ICANN's role is one generally played in our society by public entities. It is setting rules for an international communications medium of surpassing importance. That task had historically been performed by a U.S. government contractor in an explicitly public-regarding manner. ICANN is addressing important public policy issues. Further, it is implementing some of its choices via means that look uncannily like commandand-control regulation. If ICANN is to establish its legitimacy, it must be able to answer the charge that its exercise of authority is inconsistent with our ordinary understandings about public power and public policymaking.
\end{abstract}

In developing structures, procedures, and rhetoric to establish its own legitimacy, ICANN has drawn on techniques that parallel the

Copyright $@ 2000$ by Jonathan Weinberg.

$\dagger$ Professor of Law, Wayne State University. I owe thanks to Karl Auerbach, Diane Cabell, Michael Froomkin, Ellen Rony, Tony Rutkowski, Richard Sexton and, above all, Jessica Litman. I presented an earlier version of this Article in Durham, N.C., on March 3, 2000, and a different, somewhat truncated, version, under the title "Free Governance," at the Conference on a Free Information Ecology in the Digital Environment, in New York, N.Y., on April 2, 2000.

Disclaimers: I was a legal-scholar-in-residence at the Federal Communications Commission in 1997-98, where I participated via an interagency working group in the U.S. government's policymaking process regarding management of Internet names and addresses during the period leading up to the release of the Green Paper. More recently, I was the co-chair of a working group established by ICANN's Names Council to formulate recommendations regarding the deployment of new generic top-level domains. The views expressed in this Article, however, are solely my own: I do not and could not speak for the U.S. government, the Names Council, or the working group. 
justifications historically offered to defend the legitimacy of the unelected federal administrative agency. First, it has invoked what one might call the techniques of administrative law: it has, in important respects, structured itself so that it looks like a classic U.S. administrative agency, using and purportedly bound by the tools of bureaucratic rationality. Yet the techniques of administrative law are inadequate in this context, for they do not provide meaningful constraint in the absence of judicial review. In the administrative agency context, it is judicial review for rationality and statutory faithfulness that drives the agency's own commitment to process and rationality. But there is no ICANN institution that performs the function that judicial review performs for administrative agencies.

Second, ICANN has invoked the techniques of representation: it has adopted structures and procedures that make it resemble a representative (that is to say, elective) government body. ICANN's election of new at-large directors, as this Article goes to press, including candidates who campaigned on a platform of skepticism and reform, is heartening. Yet the task of representation is hardly straightforward. There may be no way to craft an elective mechanism that ensures that the immensely heterogeneous Internet community is represented, in any real sense, within ICANN's structure. Although elections can broaden the set of communities given a voice within ICANN's halls, they cannot render ICANN into a reflection of the Internet community. They can improve ICANN's decisionmaking, but they cannot reliably aggregate the preferences of the Internet world at large, and thus tell ICANN whether to adopt a disputed policy.

Finally, ICANN has invoked the techniques of consensus: it has asserted that its structure and rules ensure that it can only act in ways that reflect the consensus of the Internet community. But this is illusory. ICANN does not have procedures that would enable it to recognize consensus, or the lack of consensus, surrounding any given issue. It has commonly taken actions with no clear showing of consensus in the community at large, and its methods of determining that a particular action is supported by consensus have often seemed opaque. Indeed, there is no reason to believe that the issues over which ICANN seeks to exercise authority are ones around which any genuine consensus can be formed. 


\section{TABLE OF CONTENTS}

Introduction

I. How We Got Here

A. Early History of the Internet ...............................................192

B. Internet Addressing .............................................................194

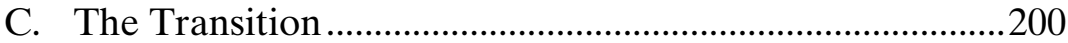

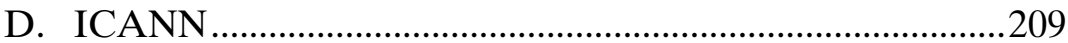

II. The Problem of Legitimacy......................................................212

III. Legitimacy and Administrative Law........................................2217

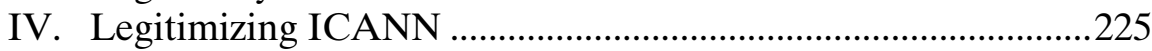

A. The Techniques of Administrative Law ............................225

B. The Techniques of Representation..................................235

C. The Techniques of Consensus ...........................................250

Conclusion

\section{INTRODUCTION}

Since late 1998, the Internet world has been the subject of an experiment in governance. That experiment is ICANN-the Internet Corporation for Assigned Names and Numbers. Two years ago, ICANN sprung into being full-grown, as if from the brow of Zeus, to take control of the Internet's infrastructure of domain name and IP address identifiers. ICANN's control over names and numbers means control over the mechanisms of visibility on the Net. Just as users need a system of telephone numbers to place telephone calls, and a system of street addresses to mail letters, users rely on the system of domain names and IP addresses to locate Internet resources.

During the past few years, questions relating to the Internet's domain name structure have become highly politically charged. ${ }^{2}$ In

1. See Letter from Jon Postel, Director, Internet Assigned Numbers Authority, to William Daley, Secretary of Commerce (Oct. 2, 1998) (announcing ICANN's incorporation, initial board of directors, and proposed bylaws), National Telecommunications and Information Administration, http://www.ntia.doc.gov/ntiahome/domainname/proposals/icann/letter.htm (on file with the Duke Law Journal).

2. See Ellen Rony \& Peter Rony, The Domain NAme Handbook viii (1998) (noting the increasing pervasiveness of legal concerns over domain names and the accompanying rising stakes); Milton Mueller, ICANN and Internet Governance: Sorting Through the Debris of "SelfRegulation," 1 INFO 497, 520 (1999) (describing and diagnosing the "tumult" of ICANN's first year); Jonathan Zittrain, ICANN: Between the Public and the Private: Comments Before Congress, 14 BERKELEY TECH. L.J. 1071, 1082 (1999) (describing ICANN's goal of bringing "an end to paralyzing fights over domain policy"); Craig Simon, The Technical Construction of Global- 
1996, Jon Postel, one of the most respected members of the Internet technical community, circulated a plan to reshape the domain name space radically through the addition of many new generic top-level domains. ${ }^{3}$ That plan was quickly endorsed ${ }^{4}$ by the Internet Society, the nonprofit membership organization that is home to key Internet technical bodies. ${ }^{5}$ It bogged down, though, as a result of fighting within the Internet community, opposition from trademark lawyers, and conflicts over jurisdiction. ${ }^{6}$ The process spawned congressional hearings $^{7}$ and lawsuits. ${ }^{8}$ We are still sorting through the debris.

The structure of the domain name space has the potential to affect Internet communication and commerce. Classification schemes

ism: Internet Governance and the DNS Crisis, at http://www.flywheel.com/ircw/dnsdraft.html (Oct. 1998) (recapping the controversy over United States privatization of Internet infrastructure management) (on file with the Duke Law Journal).

3. See Jon Postel, New Registries and the Delegation of International Top-level Domains, at http://www.newdom.com/archive/draft-postel-iana-itld-admin-01.txt (June 1996) (on file with the Duke Law Journal).

4. See Rony \& Rony, supra note 2, at 523 (noting the passage of Resolution 96-05 by ISOC, approving Postel's revised draft, and encouraging its additional refinement); Mueller, supra note 2, at 501 (noting the endorsement by the ISOC); Internet Society: Minutes of the Annual General Meeting of the Board of Trustees, Internet Society, at http://www.isoc.org/isoc/ general/trustees/mtg09.shtml (June 24-25, 1996) (recording the passage of Resolution 96-05 and endorsing Postel's proposal) (on file with the Duke Law Journal).

5. See All About ISOC, Internet Society, at http://www.isoc.org/isoc/ (last visited Aug. 17, 2000) (giving background information about the ISOC) (on file with the Duke Law Journal); Overview of the IETF, Internet Engineering Task Force, at http://www.ietf.org/overview.html (last visited Aug. 17, 2000) (providing basic information about the IETF) (on file with the Duke Law Journal).

6. See Mueller, supra note 2, at 501-02 (recounting opposition to Postel's proposition); Simon, supra note 2.

7. See generally Domain Name System Privatization: Is ICANN Out of Control?: Hearings Before the Subcomm. on Oversight and Investigations of the House Comm. On Commerce, 106th Cong. (1999) [hereinafter Domain Name System Privatization]; The Future of the Domain Name System: Hearings Before the Subcomm. on Telecomms., Trade, and Commerce Protection of the House Comm. on Commerce, 105th Cong. (1998); Transferring the Domain Name System to the Private Sector: Joint Hearings Before the Subcomms. on Basic Research and Tech. of the House Comm. on Science, 105th Cong. (1998); Internet Domain Names: Hearings Before the Subcomm. on Basic Research of the House Comm. on Science, 105th Cong. (1997).

8. See, e.g., PGMedia, Inc. v. Network Solutions, Inc., 202 F.3d 573, 576-78 (2d Cir. 2000) (holding that Network Solutions, providing domain registration services under contract with the NSF, was immune from antitrust liability and that its failure to add new top-level domain names did not violate the First Amendment); Thomas v. Network Solutions, Inc., 176 F.3d 500, 504-05 (D.C. Cir. 1999) (rejecting challenges, grounded in the Constitution, antitrust law, and the Independent Offices Appropriation Act, to domain name registration fees). 
structure the way we think. ${ }^{9}$ If the domain name space contains fifty top-level domains for commercial uses and only one for noncommercial speech, that imbalance will shape the way we use that space. Plans to expand the domain name space, in consequence, have been highly controversial. One major player is urging the creation of new Internet domain names (which currently tend to look like wayne.edu or threecats.net) such as walmart.shop. ${ }^{10}$ A different group is championing proposed names such as boeing.union or microsoft.sucks. ${ }^{11}$ Still other players see all proposals to expand the name space as profoundly threatening. ${ }^{12}$ ICANN has assumed the job of resolving these disputes. ${ }^{13}$

In this Article, I shall briefly explain the process by which ICANN came into being. I shall then turn to the legitimacy issues that have swirled around ICANN from its inception and examine the techniques that ICANN has used to address those issues. I suggest that the legitimacy questions besetting ICANN are, or should be, familiar to U.S. administrative lawyers. They parallel concerns about the legitimacy of federal administrative agencies that have been at the heart of administrative law since the beginning. The ultimate issue, in both cases, is the exercise of public power, and the creation of public policy, by an entity without democratic credentials or direct political accountability. To be sure, ICANN's legitimacy issues are highly controversial, and rightly so, while the legitimacy of the U.S. administrative agency is no longer in doubt. Yet the parallels are instructive.

I suggest in this Article that the administrative law debates over agency legitimacy are useful in understanding ICANN's responses to concerns about its own legitimacy. Indeed, ICANN's efforts mirror some of the major answers in the administrative law literature to the

9. See generally GeOfFrey C. BOWKer \& SUSAN L. STAR, SORTING Things OUT: CLASSIFICATION AND ITS CONSEQUENCES 5 (1999) ("Each . . . category valorizes some point of view and silences another.").

10. See Roger J. Cochetti, NSI, Inc.: How New, Internet Top-Level Domains Could Be Introduced Rapidly on a Sound Basis, Network Solutions, at http://www.nsol.com/policy/ gtldpaper20000419.html (last visited Aug. 17, 2000) (on file with the Duke Law Journal).

11. See Letter from James Love, Director, Consumer Project on Technology, \& John Richard, Director, Essential Information, to ICANN staff (June 10, 2000), http://www.icann.org/ yokohama/eoi16.htm (on file with the Duke Law Journal).

12. See Jessica Litman, Electronic Commerce and Free Speech, 1 J. ETHICS \& INFO. TECH. 213, 218 (1999) (recounting trademark owners' opposition to new top-level domains).

13. See, e.g., ICANN Yokohama Meeting Topic: Introduction of New Top-Level Domains, at http://www.icann.org/yokohama/new-tld-topic.htm (last visited Aug. 17, 2000) (on file with the Duke Law Journal). 
question of agency legitimacy. Understanding those parallels makes it easier to evaluate ICANN's actions and to see whether they succeed in addressing its legitimacy concerns.

\section{How We Got Here}

\section{A. Early History of the Internet ${ }^{14}$}

For a long time after computers were developed, they were solitary objects; one computer could not talk with another. Researchers achieved a milestone in 1965 when they used an ordinary telephone line to connect a computer at the Massachusetts Institute of Technology with another in California, allowing them to share programs and data across a substantial distance. ${ }^{15}$ In order to allow computers to communicate effectively, though, computer scientists had to devise an entirely new way, known as packet switching, of transmitting information over phone lines. ${ }^{16}$

A unit of the Department of Defense called the Defense Advanced Research Projects Agency, or DARPA, funded research into how to connect computers together into networks. ${ }^{17}$ With DARPA's support, scientists began to connect computers at various universities into a new network called the ARPANET. ${ }^{18}$ Data was transmitted over the ARPANET at a rate of 50,000 bits per second ${ }^{19}$-blindingly fast at the time, but not too far off the speed any ordinary user with an off-the-shelf modem can achieve today. ${ }^{20}$ In 1972, researchers developed the first e-mail program. ${ }^{21}$ This, for the first time, enabled the use of computers for long-distance person-to-person communication.

14. The next five paragraphs borrow from Jonathan Weinberg, Technology, Free Expression and the Law, 22 UPDATE ON LAW-RELATED EDUC. 4, 4-5 (1998).

15. See Barry M. Leiner et al., A Brief History of the Internet, Internet Society, at http://www.isoc.org/internet/history/brief.html\#Origins (last visited Aug. 19, 2000) (on file with the Duke Law Journal).

16. See id.

17. See id.

18. See id.

19. See id.

20. Today's modems are theoretically capable of 56 kilobits per second (kbps). In practice, "the local loop radio frequency bandwidth and the conversion from analog to digital format typically limits the transmission rate at which analog modems can send data to about $28 \mathrm{kbps}$, although speeds up to 33.6 kbps may be achieved." In re 1998 Biennial Regulatory ReviewModifications to Signal Power Limitations Contained in Part 68 of the Commission's Rules, 13 F.C.C.R. n.5 (Sept. 8, 1998).

21. See Leiner et al., supra note 15. 
Computer networks began springing up wherever researchers could find someone to pay for them. ${ }^{22}$ The Department of Energy set up two networks, NASA set up another, and the National Science Foundation (NSF) provided seed money for yet another. ${ }^{23}$ In each case, far-flung researchers were able to use the network to communicate and share their work via e-mail.

Scientists developed a technology called TCP/IP to connect all of these networks together. ${ }^{24}$ When the ARPANET adopted TCP/IP, people using ARPANET computers could communicate with people using computers on any other TCP/IP network. ${ }^{25}$ The technique of linking different networks together was referred to as internetworking or internetting, and the resulting "network of networks" was the Internet. ${ }^{26}$ By the mid-1980s, though, the number of interconnected hosts was still small. ${ }^{27}$

The National Science Foundation saw the chance to change that. NSF helped fund a high-speed backbone to link networks serving thousands of research and educational institutions around the United States. ${ }^{28}$ By 1992, there were more than one million host computers connected to the Internet. ${ }^{29}$ At the same time, scientists were devel-

\section{See id.}

23. See id.

24. See id. See generally Theodore John Socolofsky \& Claudia Jeanne Kale, Request for Comments (RFC) 1180, A TCP/IP Tutorial, at http://www.rfc-editor.org/rfc/rfc1180.txt (Jan. 1991) (on file with the Duke Law Journal). The RFCs are documents prepared by Internet technologists, from 1969 to the present, addressing underlying Internet protocols. Notwithstanding the humility of the "Request for Comments" designation, the RFCs include Internet standards adopted by the Internet Engineering Task Force as well as less authoritative documents. See Simon, supra note 2. "The Internet community developed RFCs as a mechanism for the generation of consensus on various engineering, technical and other protocols in the early days of the Internet's history." Letter from Robert P. Murphy, General Counsel, General Accounting Office, to Sen. Judd Gregg, Chairman, United States Senate Subcommittee on Commerce, Justice, State, and the Judiciary 5 n.3 (July 7, 2000), http://www.gao.gov/new.items/ og00033.pdf (on file with the Duke Law Journal) [hereinafter GAO Report]. See generally RFC Overview, at http://www.rfc-editor.org/overview.html (last visited Aug. 19, 2000) (on file with the Duke Law Journal).

25. See Leiner et al., supra note 15.

26. See Management of Internet Names and Addresses, 63 Fed. Reg. 31,741 (1998) [hereinafter White Paper]; Leiner et al., supra note 15.

27. See generally Robert H Zakon, Hobbes' Internet Timeline v5.1, Internet Society, at http://www.isoc.org/guest/zakon/Internet/History/HIT.html (last visited Sept. 20, 2000) (noting that the number of Internet hosts did not break 1000 until 1984) (on file with the Duke Law Journal).

28. See White Paper, supra note 26, at 31,741; Leiner et al., supra note 15.

29. See Zakon, supra note 27. 
oping new ways to use an Internet connection. At a research center in Switzerland, scientists developed a key new application: the World Wide Web, which permitted users to link documents, programs, or video clips residing on different machines almost anywhere in the world. ${ }^{30}$

\section{B. Internet Addressing}

In any system of networked computing, there has to be some mechanism enabling one computer to locate another. If I want to send e-mail to a buddy in Boise, the system needs to have some way to find his mail server so that it can direct the information there. Internet engineers came up with this solution: Each "host" computer connected to the Internet was assigned an Internet protocol (IP) address, which consisted of a unique 32-bit number, usually printed in dotted decimal form, such as 128.127.50.224. Dr. Jon Postel of the University of Southern California's Information Sciences Institute (ISI) assumed the task of assigning blocks of IP addresses to computer networks. ${ }^{31}$ Because no two computers had the same IP address, ${ }^{32}$ it was possible to locate any computer on the Internet simply by knowing its IP address. TCP/IP made possible a system of routing that permitted a user to dispatch a message onto the Internet, knowing only the IP address of the computer he wished to reach, with confidence that the message would eventually reach its intended destination. $^{33}$

30. See Tim Berners-LeE, WeAving the Web 28 (1999).

31. See Jon Postel, RFC 790, Assigned Numbers, at http://www.rfc-editor.org/rfc/rfc790.txt (Sept. 1981) (on file with the Duke Law Journal). The job of IP address allocation was transferred to the Network Information Center, then operated by the Stanford Research Institute, in 1987. See S. Romano \& M. Stahl, RFC 1020, Internet Numbers, at http://www.rfceditor.org/rfc/rfc1020.txt (Nov. 1987) (on file with the Duke Law Journal). In 1992, the job moved to Network Solutions. See White Paper, supra note 26, at 31,742. Still later, day-to-day allocation tasks were taken over by three regional IP registries (ARIN in North America, RIPE in Europe, and APNIC in the Asia/Pacific region). See id. Dr. Postel, though, remained at the top of the IP address allocation hierarchy throughout. See id.

32. This is somewhat oversimplified as a description of computer networks today. A technique known as network address translation can allow a computer to function using an address that is unique only within that computer's local network. See Jonathan Weinberg, Hardware-Based ID, Rights Management, and Trusted Systems, 52 StAN. L. ReV. 1251, 1260 n.22 (2000). More simply, a user can piggyback on the IP address of a remote computer by logging into a shell account on that computer. See id.

33. For an explanation of how routing works, see RONY \& RONY, supra note 2, at 50-55; Socolofsky \& Kale, supra note 24, at 2-8. 
In addition to an IP address, each host computer had a name, such as SRI-NIC. A Network Information Center maintained a hosts.txt table translating names to IP addresses for every host. ${ }^{34} \mathrm{~A}$ user could send e-mail specifying only the name of the relevant host; his computer would consult the hosts.txt table to determine the relevant IP address. There were two advantages to this dual system of names and addresses. ${ }^{35}$ First, IP addresses were opaque and hard to remember. Names were rather more user-friendly. It was inconvenient for a user to have to remember and type in a different IP address for every Internet resource he sought to access or e-mail message he wished to send. It was much easier to use a short name with semantic meaning. Second, the use of names made it possible for network operators to change the configuration of their networks, and therefore change the IP addresses associated with various machines, without disrupting communications with the outside world. ${ }^{36}$

This system worked well so long as the number of computers attached to the Internet was small. As that number grew, however, it became clear that the Internet needed a more sophisticated addressing structure than the hosts.txt table could provide. By 1983, the size of that table and the frequency of its updates were "near the limit of manageability." ${ }^{, 37}$ Accordingly, scientists, including Postel and Paul Mockapetris, also of the Information Sciences Institute, developed the "domain name system" (DNS). ${ }^{38}$ The domain name system retains the user-friendliness of mapping each IP address to a domain name

34. See A. Michael Froomkin, Wrong Turn in Cyberspace: Using ICANN to Route Around the APA and the Constitution, 50 DUKE L.J. 17, 51-52 (2000); Elisabeth Feinler et al., RFC 810, DoD Internet Host Table Specification, at http://www.rfc-editor.org/rfc/rfc810.txt (Mar. 1, 1982) (on file with the Duke Law Journal); M.D. Kudlick, RFC 608, Host Names On-Line, at http://www.rfc-editor.org/rfc/rfc608.txt (Jan. 10, 1974) (on file with the Duke Law Journal).

35. Jon Postel described the dual system succinctly: "A name indicates what we seek. An address indicates where it is." RFC 791, DARPA Internet Program Protocol Specification, at http://www.rcf-editor.org/rfc/rfc791.txt (Sept. 1981) (on file with the Duke Law Journal).

36. Network administrators changing their computers' IP addresses needed only to update their name to IP address mappings so that the computers retained the same names. See Ted Byfield, DNS: A Short History and a Short Future, 4 FIRST MONDAY 3, II 34 (Mar. 1, 1999) ("The benefit that [name-number mapping] offers is its 'higher level of abstraction'-a stable addressing layer that permits more reliable communications across networks where changing IP numbers change and heterogeneous hardware/software configurations are the norm."), at http://www.firstmonday.dk/issues/issue4_3/byfield/index.html (on file with the Duke Law Journal).

37. P. Mockapetris, RFC 882, Domain Names-Concepts and Facilities, at http://www.rfceditor.org/rfc/rfc882.txt (Nov. 1983) (on file with the Duke Law Journal).

38. See id. 
such as threecats.net or law.wayne.edu. ${ }^{39}$ The new system differs from the old approach, though, in key respects. ${ }^{40}$

First, the DNS defines a hierarchical name space. That name space is divided into top-level domains, or TLDs. Each top-level domain is divided into second-level domains, and so on. ${ }^{41}$ Under the plan developed by Postel and Mockapetris, there were seven generic, three-letter top-level domains: .com, .net, .org, .edu, .gov, ${ }^{42} . \mathrm{mil}^{43},{ }^{43}$ and .int. ${ }^{44}$ In addition, there were two-letter country code top-level domains such as .jp, .us, and .fr. ${ }^{45}$ At the outset, it was thought that .com would be used by commercial entities, net by entities involved with the Internet networking infrastructure, .org by nonprofit organizations, and edu by educational institutions. ${ }^{46}$ Today, the restrictions on the first three of these have long since fallen away. ${ }^{47}$ The largest toplevel domain by far is .com, with more than sixteen million secondlevel domain names as of this writing, ${ }^{48}$.net and .org come next.

39. A given IP address may map to more than one domain name, and, in some circumstances, more than one IP address may map to a single domain name.

40. See generally Robin Murphy, From Names to Numbers: A Brief Overview of the Domain Name System, 2 INTERNIC News 4 (Apr. 1997) (describing key characteristics of the Domain Name System), at http://www.harbornet.com/ken/nicv2i04.txt (on file with the Duke Law Journal).

41. See White Paper, supra note 26, at 31,742.

42. Originally, .gov was intended for government offices of any sort. Later, its management was transferred to the Federal Networking Council, and it was reserved for U.S. federal government agencies. See J. Postel, RFC 1591, Domain Name System Structure and Delegation, at http://www.rfc-editor.org/rfc/rfc1591.txt (Mar. 1994) (on file with the Duke Law Journal).

43. This domain is reserved for U.S. military sites. See id.

44. This domain is reserved for international treaty organizations. See id.

45. See id.; see also Root-Zone Whois Information, Internet Assigned Numbers Authority, at http://www.iana.org/cctld/cctld-whois.htm (last visited Oct. 6, 2000) (listing the country-code domains) (on file with the Duke Law Journal).

46. See RonY \& RonY, supra note 2, at 44-47; Postel, supra note 42.

47. Indeed, Network Solutions, until recently the monopoly domain name registrar, now urges customers that "the best way to protect the uniqueness of your online identity and brands" is to register their second-level domains three times, in each of .com, .net, and .org. This generates three times the registration fees. See Frequently Asked Questions-What Do .COM, .NET and .ORG Signify in a Web Address?, at http://www.networksolutions.com/help/ general.html\#name6 (last visited Aug. 18, 2000) (on file with the Duke Law Journal); see also Frequently Asked Questions About BAP Users: New Domain Name Registrations-What Are the Guidelines for Registering an .EDU Web Address?, at http://www.networksolutions.com/help/ faq-newreg-bap.html (last visited Aug. 18, 2000) (stating that the .edu address is reserved for four-year colleges and universities) (on file with the Duke Law Journal).

48. See E-mail from Richard J. Sexton, Founder, VRx Network Services, Inc., to Professor Jonathan Weinberg, Wayne State University Law School (Aug. 8, 2000) (on file with the Duke Law Journal). 
Within the name space pyramid, the structure replicates itself. The owner of each second-level domain is at the apex of a pyramid consisting of the third-level domains (if any) within that second-level domain, and so on. This hierarchy makes possible (but does not mandate) functional, geographical, or other organization of any portion of the name space. ${ }^{49}$

The hierarchy also makes it easier for name-to-number translation to be distributed. There is no single central server that must be queried every time an Internet-connected computer needs to map a domain name to an IP address. Rather, at the apex of the DNS pyramid is a set of thirteen root servers, ${ }^{50}$ each of which lists the IP addresses of the computers containing the zone files for each of the toplevel domains. At the next level are the computers holding those toplevel domain zone files, each of which lists the IP addresses of the name servers for each second-level domain it controls, and so on. When a user looking for a particular Internet resource types in a domain name, his computer begins at the bottom of the pyramid: it queries a set of local DNS servers, specified in its software, to find the IP address corresponding to that domain name. If those local servers do not know the answer, they move the request up the line.

By virtue of the structure of the DNS, the ability to modify (or to refuse to modify) the root zone files in the root servers carries with it considerable power. If a user types in a domain name incorporating a top-level domain that is unknown to the root servers, then the DNS will be unable to find the corresponding computer. ${ }^{51}$ The power to control the root servers is the power to decide (1) which top-level domains are visible in the name space and (2) which name servers are authoritative for those top-level domains-that is, which entities get to say who controls the various second-level domains in that top-level domain.

On the other hand, there is no requirement that any particular end user send his DNS queries to a name server that references the root zone described above. Users can point their computers at entirely different DNS servers that, in turn, point to different root serv-

49. See generally Postel, supra note 42 (discussing the structure and delegation of domain name space).

50. See Root Nameserver Year 2000 Status, at http://www.icann.org/committees/dns-root/ y2k-statement.htm (July 15, 1999) (listing the root servers) (on file with the Duke Law Journal).

51. See RonY \& RonY, supra note 2, at 516-17; Zittrain, supra note 2, at 1080. 
ers, referencing a different set of top-level domains. ${ }^{52}$ Such alternative top-level domains and alternative root servers in fact exist, so that if one points one's computer at the right DNS server, one can send email to addresses that the rest of the Internet does not recognize, such as < richard@vrx.zoo $>$ or $<$ richard@tangled.web $>.^{53}$ Very few Internet users, though, look to alternative root servers. The vast majority rely on the single set of authoritative root servers, historically supervised by Jon Postel, that have achieved canonical status. ${ }^{54}$

Once the DNS got underway in 1985, the day-to-day job of registering second-level domains in the generic top-level domains was handled by the Stanford Research Institute (SRI) under contract to the U.S. Department of Defense. ${ }^{55}$ The Defense Department, which had long funded ISI as part of its funding of almost all of the Internet's early development, ${ }^{56}$ also entered into contracts under which it funded the activities of Dr. Postel and other Information Sciences Institute staff in coordinating IP address allocation and oversight of the domain name system. ${ }^{57}$ These activities came to be referred to as the Internet Assigned Numbers Authority (IANA). ${ }^{58}$ Later on, the National Science Foundation took over the role of funding the civilian part of the Internet infrastructure. ${ }^{59}$ The National Science Foundation entered into a cooperative agreement with a company named Network Solutions, Inc. (NSI) to perform the registration services that had been handled earlier by SRI. ${ }^{60}$ NSI agreed to register second-level

52. See How to Use New Domain Names, Open Root Server Confederation, at http://support.open-rsc.org/How_To/ (last visited Aug. 18, 2000) (on file with the Duke Law Journal).

53. See id.

54. BIND, the software running most Internet name servers, ships with a root.cache file listing the canonical root servers as authoritative. See Name Server Operations Guide for BIND, Computer System Research Group, at http://www.dns.net/dnsrd/docs/bog/bog-sh-5.html\#sh-5.3 (last visited Aug. 18, 2000) (on file with the Duke Law Journal); Simon, supra note 2.

55. See PGMedia, Inc. v. Network Solutions, Inc., 51 F. Supp. 2d 389, 393 (S.D.N.Y. 1999), aff'd, 202 F.3d 573 (2d Cir. 2000).

56. See E-mail from Anthony M. Rutkowski, Vice-President, Internet Strategies, VerisignNSI, to Professor Jonathan Weinberg, Wayne State University Law School (July 5, 2000) (on file with the Duke Law Journal).

57. See PGMedia, 51 F. Supp. $2 \mathrm{~d}$ at 393.

58. See Jon Postel, RFC 1083, IAB Official Protocol Standards, at http://blitzen.canberra.edu.au/RFC/rfc/rfc1083.html (Dec. 1988) (on file with the Duke Law Journal). This is the first reference in the RFCs to IANA.

59. See White Paper, supra note 26, at 31,742.

60. See id. NSI had already been processing registrations for a short period of time pursuant to a subcontract from Government Services, Inc., which had succeeded SRI. See PG Media, 51 F. Supp. 2 d at 393. 
domains in .com, .net, .org, and .edu and to maintain those top-level domains' master databases. Those services were underwritten by the National Science Foundation and were free to users. ${ }^{61}$

Under arrangements made by various players in the domain name space through the late 1990s, NSI administered the key root server, known as the "A" root server, but policy authority over the contents of the "A" root rested with Jon Postel and IANA. ${ }^{62}$ It was Postel who was responsible for deciding whether a new country code domain should be added to the root zone and which entity should be responsible for administering that domain. ${ }^{63}$ It was Postel and IANA who were in the end responsible for resolving disputes over the allocation of IP addresses. ${ }^{64}$

Most of the thirteen root server operators, for their part, had no formal relationship with IANA, NSI, or a U.S. government funding agency. ${ }^{65}$ In theory, they could have installed on their machines inconsistent copies of the root zone file-recognizing different top-level domains, or recognizing different firms as having authority to say who should control the second-level domains in a given top-level domain. The latter would have been problematic, because it would have meant that the IP address to domain name mapping a user encountered would depend on the fortuity of the root server his query happened to hit. In fact, however, the root server operators mirrored the changes (and only those changes) made to the "A" root, following the direction of IANA in large part out of personal loyalty to, and respect for, Jon Postel. ${ }^{66}$

61. See id. at 392; NSF Cooperative Agreement No. NCR-9218742, at http://www.networksolutions.com/legal/internic/cooperativeagreement/agreement.html (Jan. 1, 1993) (on file with the Duke Law Journal) [hereinafter NSF Cooperative Agreement].

62. The standards governing that policy authority are set out in Postel, supra note 42.

63. See id.

64. Under RFC 1174, the responsibility for the allocation and assignment of numeric identifiers rests with IANA or its delegatees. When NSI took day-to-day responsibility for number allocation in 1992, its cooperative agreement with the National Science Foundation directed it to provide its services in accordance with that declaration. See NSF Cooperative Agreement, supra note 61 .

65. Letter from Andrew J. Pincus, General Counsel, Department of Commerce, to Rep. Thomas J. Bliley, Jr., Chairman, United States House Committee on Commerce (July 8, 1999) ("[A]s the Internet has grown, operation of the root server system has remained ad hoc, in that it continues to be administered by 'volunteers' who are not bound by any legal obligation to work together."), National Telecommunications and Information Administration, http://www.ntia.doc.gov/ntiahome/domainname/blileyrsp.htm (on file with the Duke Law Jour$n a l)$.

66. See Simon, supra note 2. 


\section{The Transition ${ }^{67}$}

In 1994, Jon Postel published a Request for Comments (RFC) ${ }^{68}$ summarizing the existing top-level domain name structure and noting: "It is extremely unlikely that any other [generic] TLDs will be created." ${ }^{\circ 9}$ The Net, however, was coming of age. By 1995, it had been more than twenty-five years since the initial establishment of the ARPANET. Businesses were beginning to use the Internet for commercial purposes. More than 100 countries were now connected to the Internet and could boast their own top-level domains. ${ }^{70}$ The World Wide Web, which had become the dominant Internet application, was now truly worldwide. As the number of registrations began to rise, NSI and the National Science Foundation negotiated an amendment to the cooperative agreement under which NSF would no longer pay for registrations; instead, NSI would charge a $\$ 50$ annual fee to each domain name registrant. ${ }^{71}$

The NSI fee crystallized growing unhappiness with the structure of the domain name system. Registrants wondered why, in seeking to register names in the generic top-level domains, they were stuck with the service provided by, and the fees charged by, the NSI monopoly. ${ }^{72}$ NSI also generated animosity with its domain name dispute policies, under which it asserted the right to (and did) suspend any domain name upon receiving a complaint from a trademark owner, without

67. What follows is a highly selective account of some of the events of 1994-99. The events of the "DNS wars" leading up to the formation of ICANN could easily fill books. I seek to offer just enough detail to give the reader a general understanding of ICANN's origins. For longer discussions, see the sources cited supra note 2.

68. See supra note 24 and accompanying text (summarizing the history and purpose of RFCs).

69. Postel, supra note 42 .

70. The hundredth county code top-level domain had been assigned in 1993. See E-mail from Anthony M. Rutkowski, Vice-President, Internet Strategies, Verisign-NSI, to Professor Jonathan Weinberg, Wayne State University Law School (July 24, 2000) (setting out the historical emergence of the Internet DNS root and top-level domains from 1985 to 1994) (on file with the Duke Law Journal).

71. See Rony \& Rony, supra note 2, at 149; NSI-NSF Cooperative Agreement No. NCR9218742, Amendment 4, at http://www.networksolutions.com/legal/internic/cooperativeagreement/amendment4.html (Sept. 13, 1995) (on file with the Duke Law Journal).

72. See, e.g., E-mail from Jon Postel, Director, Internet Assigned Numbers Authority, to Rick Adams, Chairman and Chief Technical Officer, UUNET (Sept. 15, 1995) ("I think this introduction of charging by [NSI] for domain registrations is sufficient cause to take steps to set up a small number of alternative top-level domains managed by other registration centers. I'd like to see some competition between registration services to encourage good service at low prices."), World Internetworking Alliance, http://www.wia.org/pub/postel-iana-draft13.htm (on file with the Duke Law Journal). 
regard to whether the trademark owner had a superior legal claim to the domain name. ${ }^{73}$ Finally, there was growing consensus in the technical community that the architecture would support many more toplevel domains than had been authorized so far.

Accordingly, in 1996, Dr. Postel suggested that IANA authorize up to 150 new generic top-level domains to be operated by new registries. ${ }^{75}$ As the proposal went through successive iterations, IANA and the Internet Society ${ }^{76}$ formed an elaborate, internationally based "Internet Ad Hoc Committee" (IAHC) to consider the question of adding new top-level domains. The IAHC included representation from, among others, the International Telecommunications Union (ITU), the International Trademark Association (INTA), and the World Intellectual Property Organization (WIPO). ${ }^{77}$ The INTA representative urged that the number of proposed new domains be cut considerably. ${ }^{78}$ Under pressure, the IAHC ultimately generated a

73. See Rony \& Rony, supra note 2, at 147; Carl Oppedahl, Avoiding the Traps in the New Rules for Registering a Domain Name, N.Y. L.J., Aug. 8, 1995, at 5.

74. See Postel, supra note $3, \S 1.5$.2 ("It is considered undesirable to have enormous numbers $(100,000+)$ of top-level domains for administrative reasons and the unreasonable burden such would place on organizations such as the IANA. It is not, however, undesirable to have diversity in the top-level domain space ....").

75. See id. §5.6.

76. See supra note 5 and accompanying text.

77. See Simon, supra note 2. The members of the IAHC were Sally M. Abel, a partner in the law firm of Fenwick \& West, representing the International Trademark Association; Dave Crocker, a director of the Internet Mail Consortium, representing IANA; Donald M. Heath, President and CEO of the Internet Society; Geoff Huston, Technical Manager of Telstra Internet, representing the Internet Architecture Board; David W. Maher, a partner in the law firm of Sonnenschein Nath \& Rosenthal, representing the Internet Society; Perry E. Metzger, President of Piermont Information Systems, Inc., representing IANA; Jun Murai, an associate professor of environmental information at Keio University, representing the Internet Society; Hank Nussbacher, a networking consultant working with IBM Israel, representing the Internet Architecture Board; Robert Shaw, an official of the International Telecommunications Union; George Strawn, Chair of the (U.S.) Federal Networking Council; and Albert Tramposch, representing the World Intellectual Property Organization. See id.; Final Report of the International Ad Hoc Committee: Recommendations for Administration and Management of gTLDs, at http://www.gtld-mou.org/draft-iahc-recommend-00.html (last modified Feb. 4, 1997) (on file with the Duke Law Journal) [hereinafter Final Report].

78. See Simon, supra note 2. Dave Crocker, an IAHC member, has reported that the INTA representative (Ms. Abel) "put forward that they would prefer zero new gTLDs. Acknowledging that that position was not viable against the consumer desire for additional gTLDs, they instead negotiated for a careful increment.” Posting of Dave Crocker, dhc@dcrocker.net, to owner-domain-policy@internic.net (Aug. 7, 2000), at http://lists.netsol.com/cgi-bin/ wa? $\mathrm{A} 2=$ ind $0008 \& \mathrm{~L}=$ domain-policy $\& \mathrm{D}=1 \& \mathrm{~T}=0 \& \mathrm{O}=\mathrm{D} \& \mathrm{~F}=\& \mathrm{~S}=\& \mathrm{P}=41821$ (on file with the Duke Law Journal). A different report, prepared by the bodies established under the IAHC proposal, described the intellectual property community as "adamant" that the top-level domain 
proposal for the addition of just seven new top-level domains as an initial matter. ${ }^{79}$

Under this proposal, a variety of businesses were to become "registrars," interacting with domain name registrants and taking their registrations. ${ }^{80}$ The registrars would join together in a nonprofit organization known as the Council of Registrars, or CORE. CORE would actually maintain the "registry," a single set of servers containing the authoritative zone files for all of its new top-level domains. ${ }^{81}$ A new entity known as the Policy Oversight Committee would decide policy questions, including which new top-level domains would be added, and on what timetable. ${ }^{82}$ The proponents were hopeful that with the expiration of the cooperative agreement under which NSI registered names into the existing generic top-level domains, CORE could take over the operation of those top-level domains as well. ${ }^{83}$

The IAHC proposal ran into opposition on several fronts. Some saw the proposal as a takeover of the domain name system by a lim-

space not undergo immediate large expansion. gTLD-MoU Frequently Asked Questions-Why Did You Choose These Names and Why Only Seven?, at http://www.gtldmou.org/docs/faq.html\#2.2 (last modified June 1, 1998) (on file with the Duke Law Journal).

79. See Final Report, supra note 77, $\$ 3.1$ (listing the seven proposed domains). The official website maintaining documents created under the IAHC framework later explained:

We only selected seven as an initial number since given that the DNS is critical to the operation of the Internet, we thought it prudent to define initial changes on a relatively modest scale, with later evaluation and modification as appropriate. In addition, the trademark community has repeatedly expressed the opinion of its reticence that new gTLDs should be created because it increases their need to police for domain name registrations for trademark violations. Seven represented a compromise between different viewpoints within the IAHC and public comments on the number of gTLDs to introduce in a first phase. The intellectual property community was especially adamant that the viability of the [trademark] dispute resolution processes . . . be demonstrated before further expansion of the top-level domain space.

gTLD-MoU Frequently Asked Questions, supra note 78.

80. Final Report, supra note 77, $\S \S 2.2$ (defining "registrar"), 4.1 .1 (proposing the selection of multiple registrars).

81. Id. $\S \S 2.2$ (defining "registry"), 5.1.2 (describing CORE's operations). In fact, CORE contracted that service out to a for-profit company known as Emergent. See CORE Press Release: CORE Announces Signing of Letter of Intent with Emergent Corporation, at http://www.gtld-mou.org/press/core-1.html (Oct. 24, 1997) (on file with the Duke Law Journal).

82. Final Report, supra note 77, §5.1.1 (describing POC).

83. See Mueller, supra note 2, at 502 (noting that the NSI "correctly saw its control of the lucrative .com domain as the target of the [IAHC] shared registry model"); Simon, supra note 2 (noting that the IAHC plan "constituted a mechanism that could serve to take possession of the NSI registry ... when the Cooperative Agreement expired"). 
ited, closed set of institutional interests. ${ }^{84}$ Some objected that those who had established IAHC were drawn primarily from the Internet engineering community, rather than newer Internet constituencies, including businesses interested in the Internet as a vehicle for electronic commerce. ${ }^{85}$ There was a sense that IAHC was noninclusive and secretive, and that notwithstanding the fact that in the past Internet architecture questions had been decided by Internet engineers operating in their own professional circles, it was inappropriate for domain name questions in the new Internet world to be decided by an essentially self-appointed group. ${ }^{86}$ Others objected that IAHC included representatives of organizations, including the International Telecommunications Union and the International Trademark Association, that were seen as hostile to traditional Internet values. ${ }^{87}$ There were objections that the IAHC solution would inappropriately institutionalize centralized control over the domain name space. ${ }^{88}$ NSI mounted a well-funded campaign against the IAHC solution, directly and through proxies. The IAHC cause was not helped in the United States by the fact that the proposed new organizations were to be

84. See, e.g., Internet Domain Names, Part II: Hearings Before the House Comm. on Science, 105th Cong. 162-63 (1997) (testimony of Anthony M. Rutkowski) (examining antitrust and governance issues) [hereinafter Internet Domain Names Hearings]; RONY \& RONY, supra note 2, at 534-40 (analyzing the self-regulation model); Courtney Macavinta \& Margie Wylie, Domain Plan Called Power Grab, CNET News (June 4, 1997) (describing criticism of the IAHC plan as an unrepresentative "power grab"), at http://news.cnet.com/news/0-1005-200319458.html?cnet.tkr (on file with the Duke Law Journal).

85. See Keith Gymer, BT Response to U.S. Government Green Paper: A Proposal to Improve Technical Management of Internet Names and Addresses, National Telecommunications and Information Administration, at http://www.ntia.doc.gov/ntiahome/domainname/130dftmail/ BT.htm (Mar. 23, 1998) (arguing that "representative regional and mainstream consumer and business organizations" should have the key voice in Internet governance, not "technical members of the so-called 'internet community") (on file with the Duke Law Journal).

86. See RonY \& RonY, supra note 2, at 536-40.

87. See Internet Domain Names Hearings, supra note 84, at 162-63 (testimony of Anthony M. Rutkowski) (objecting that the IAHC included representatives of the International Telecommunications Union); Mueller, supra note 2, at 502 (noting the criticism that the Internet was being sold out to trademark interests); Simon, supra note 2 (discussing "the impression among the IAHC's increasingly infuriated critics that trademark interests had dominated the process").

88. See Internet Domain Names Hearings, supra note 84, at 162-63 (testimony of Anthony M. Rutkowski) (urging that the IAHC path represented an anachronistic, nineteenth-century model of centralized, top-down "public resource" management); Einar Stefferud, Global Sense Musings (on the Internet Paradigm), World Internetworking Alliance, at http://www.wia.org/pub/stef-internet-paradigm.html (last modified Sept. 11, 1997) (urging that IAHC's attempts to centralize control over TLD naming in an official root zone were misguided) (on file with the Duke Law Journal). 
based in Europe, or by a notable deficit of diplomatic skills on the part of some of its founders.

At the same time, it was increasingly clear that the status quo could not long continue. Although Dr. Postel had the loyalty and respect of a wide consensus of the community, his informal leadership was no longer enough. "What happens," many worried, "if Jon Postel gets hit by a beer truck?" 89 The U.S. government convened a working group, which included representatives from the White House Office of Science and Technology Policy, the National Telecommunications and Information Administration, the Patent and Trademark Office, the National Science Foundation, the Department of Defense, the Department of Justice, the Department of State, the Federal Communications Commission, and other agencies, to figure out what should be done. In July 1997, the National Telecommunications and Information Administration (NTIA) released a public request for comments regarding desirable characteristics of Internet governance and the domain name space. ${ }^{90}$ Simultaneously, key members of the working group began negotiating with Postel about reorganizing IANA into an entity with a more formal and robust management structure and more formal accountability to the international Internet community.

The working group members were skeptical of the IAHC proposals; they saw it as their job to figure out which structures and policy choices would best effectuate a healthy Internet name space and governance process and then to make it so. ${ }^{91}$ At the same time, there was considerable uncertainty about the U.S. government's legal authority to impose its policy choices. Although IANA's functions were still performed under contract to the Department of Defense, and NSI registered names pursuant to a cooperative agreement with the National Science Foundation, the degree to which this translated

89. Declan McCullagh, NeTLY News (Apr. 16, 1997), at http://www.interestingpeople.org/199704/0039.html (on file with the Duke Law Journal). McCullagh continued:

No longer can Jon Postel, a little-known but highly trusted network guru, run the Internet Assigned Numbers Authority (IANA) and decide what top-level domains should exist. Not only is he being battered by lawsuits, what happens if he drops dead tomorrow? I don't mean to be morbid here, but this is important stuff in highpowered telecom circles: The Federal Networking Council's Advisory Committee took time this week to seriously contemplate the "Jon Postel getting hit by a beer truck" scenario.

Id.

90. See Department of Commerce, Request for Comments on the Registration and Administration of Internet Domain Names, 62 Fed. Reg. 35,896 (1997).

91. This characterization rests on my observation as a member of that working group. 
into formal legal authority on the part of the U.S. government was hardly clear. The agreements did not unambiguously obligate IANA and NSF to follow the government's orders regarding the root zone; and it was even murkier what would happen if the agreements were not renewed. ${ }^{92}$

In January 1998, the U.S. government released A Proposal to Improve Technical Management of Internet Names and Addresses, commonly referred to as the Green Paper. ${ }^{93}$ The Green Paper did not even mention the IAHC process. Indeed, it had already become plain that the IAHC proposal was going nowhere: CORE's new top-level domains could not become visible unless appropriate changes were made in the root zone files. NSI, however, which had operational control over the "A" root, was making no changes without the authorization of the U.S. government, and the U.S. government had directed it to maintain the status quo. ${ }^{94}$

The Green Paper proposed the creation of a new not-for-profit corporation, "operat[ing] as a private entity for the benefit of the Internet as a whole," to manage domain names, IP addresses, and the

92. In 1997, in connection with a lawsuit filed against it by PGMedia, NSI requested permission from the National Science Foundation to add new generic top-level domains to the root zone. See Name.Space, Inc. v. Network Solutions, Inc., 202 F.3d 573, 579 (2d Cir. 2000). The National Science Foundation, after consulting with the working group, directed NSI to take no action; NSI, whose litigation strategy sought to avoid antitrust liability on the ground that it had no discretionary authority over the root, complied. See id. at 579-80. The cooperative agreement was scheduled to expire soon, though, and the outcome of negotiations to extend it was unclear. Later on, NSI and the National Telecommunications and Information Administration (which had succeeded the National Science Foundation as the U.S. party to the cooperative agreement) did extend the agreement and explicitly agreed that NSI must "request written direction from an authorized [Department of Commerce] official before making or rejecting any modifications, additions or deletions to the root zone file." Cooperative Agreement No. NCR-9218742, Amendment 11, at http://www.networksolutions.com/legal/internic/cooperative-agreement/ amendment11.html (Oct. 6, 1998) (on file with the Duke Law Journal) [hereinafter Amendment $11]$.

The extent of the U.S. government's control over IANA was still more problematic. In January of 1998, for a short period of time, Jon Postel directed the root server operators not controlled by NSI or the U.S. government to take their authoritative copy of the root zone directly from his own server. In theory, this could have enabled him to make changes to the root zone without the cooperation of NSI or the U.S. government. Under government pressure, though, Postel quickly ended what he later referred to as a "test." See Froomkin, supra note 34, at 64-65; Simon, supra note 2.

93. Department of Commerce, National Telecommunications and Information Administration, Improvement of Technical Management of Internet Names and Addresses, 63 Fed. Reg. 8,825 (1998) [hereinafter Green Paper].

94. See Amendment 11, supra note 92. 
root server network. ${ }^{95}$ Current IANA staff would move to the new organization. The U.S. government would transfer existing IANA functions, the root system, and the appropriate databases to the new corporation; the government would "participate in policy oversight to assure stability" for no more than two years. ${ }^{96}$ The Green Paper emphasized that the new organization and its board "must derive legitimacy from the participation of key stakeholders." "The board, therefore, was to include representatives of membership organizations relating to domain names, IP addresses, and Internet technical parameters, as well as representatives of "the direct interests of Internet users"-commercial, not-for-profit, and individual. ${ }^{98}$ The Green Paper suggested that seats on the organization's initial board might include three directors from a membership association of regional number registries, two directors named by the Internet Architecture Board, two members designated by a not-yet-created membership association of domain name registries and registrars, seven members designated by a not-yet-created membership association of Internet users, and the new corporation's CEO. ${ }^{99}$

The structure described in the Green Paper called for a great deal of institution building: after all, neither the new corporation itself nor the various membership associations actually existed. The document, however, radiates an insouciant confidence that these institutions could be created without overwhelming difficulty. As far as substantive policies were concerned, the Green Paper urged that domain name registration in any given top-level domain be performed by competing registrars (as in the IAHC model). ${ }^{100}$ It went further to urge that the domain name infrastructure be expanded to include multiple new registries, each maintaining the zone file for at least one new top-level domain. ${ }^{101}$ In the short run, the Green Paper proposed that while the new corporation was getting off the ground, five new registries be selected, each operating a single new top-level domain. ${ }^{102}$

In retrospect, the Green Paper is notable for its carefree confidence that the government could straightforwardly implement its rec-

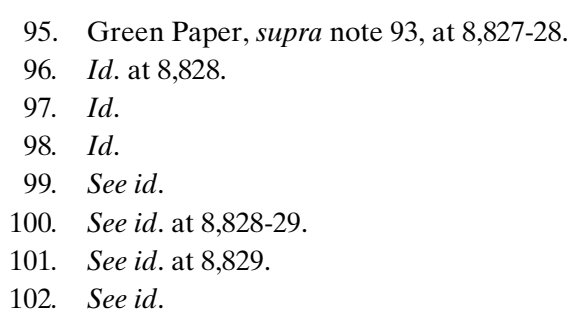


ommendations. The document, however, inspired strong protest from a variety of groups. ${ }^{103}$ When the U.S. government issued its White Paper four months later, things had changed. The new document ex-

103. See, e.g., Capital Networks' (CORE Registrar) Response to the Green Paper, National Telecommunications and Information Administration, at http://www.ntia.doc.gov/ntiahome/ domainname/130dftmail/03_09_98.htm (Mar. 10, 1998) (stating that the Green Paper illadvisedly limits the number of gTLDs and is based upon a flawed competitive model) (on file with the Duke Law Journal); Comments of Bell Atlantic Corporation on Improvement of Technical Management of Internet Names and Addresses, National Telecommunications and Information Administration, at http://www.ntia.doc.gov/ntiahome/domainname/130dftmail/Bell.htm (Mar. 23, 1998) ("The creation of up to five new generic Top-level domains (gTLDs) is fundamentally flawed and ought to be reconsidered.") (on file with the Duke Law Journal); Comments of the Internet Society in Regards to the Department Of Commerce National Telecommunications and Information Administration 15 CFR Chapter XXIII [Docket No. 980212036-803601] Improvement of Technical Management of Internet Names and Addresses ("Green Paper"), National Telecommunications and Information Administration, at http://www.ntia.doc.gov/ ntiahome/domainname/130dftmail/03_17_98.htm (Mar. 17, 1998) (stating that the policy decisions reflected in the Green Paper should be left to IAHC's "bottom-up" consensus-building process) (on file with the Duke Law Journal); DNS Comments of America Online, Inc. on Improvement of Technical Management of Internet Names and Addresses, National Telecommunications and Information Administration, at http://www.ntia.doc.gov/ntiahome/domainname/ 130dftmail/scanned/AOL.htm (Mar. 23, 1998) (asserting that the Green Paper slights participation by the international community and that no "concrete need exists that would justify an increase in the number of gTLDs in the near term") (on file with the Duke Law Journal); Melbourne IT Comments on Internet Domain Name System, National Telecommunications and Information Administration, at http://www.ntiahome/domainname/130dftmail/03_22_98.htm (Mar. 23, 1998) (stating that the Green Paper is too U.S.-centric, reflects ill-considered competition policy, inadequately addresses international trademark issues, and would "stifle international competition, negatively impact the growth of the Internet, and threaten the burgeoning electronic commerce market") (on file with the Duke Law Journal); Reply of the European Community and Its Member States to the US Green Paper, National Telecommunications and Information Administration, at http://www.ntiahome/domainname/130dftmail/03_20_98.htm (Mar. 20, 1998) (complaining that the Green Paper does not "recognize the need to implement an international approach," is unhelpful in addressing trademark issues, and does not go far enough to ensure fair competition, and recommending that "the US Administration limit its direct regulatory intervention in the Internet only to those relationships which fall clearly under existing contract between the Agencies of the US Government and their contractors and that all other decisions be referred to an appropriate internationally constituted and representative body") (on file with the Duke Law Journal); Response to Green Paper from Demon Internet, National Telecommunications and Information Administration, at http://www.ntiahome.domainname/130dftmail/03 05 98.htm (Mar. 5, 1998) (stating that competing registries are unjustifiable and undesirable, the Green Paper approach treats NSI too favorably, and any United States government interference in the community consensus process represented by CORE is ill-advised) (on file with the Duke Law Journal); E-mail from Marc Berejka, Federal Regulatory Affairs Manager, Microsoft Corporation, to the U.S. Department of Commerce (Mar. 23, 1998) ("We ... urge the Department not to hasten to introduce 5 new gTLDs as its proposals suggests [sic], but rather to take a more measured deliberate approach."), National Telecommunications and Information Administration, http://www.ntia.doc.gov/ntiahome/domainname/130dftmail/03_23_98-10.htm (on file with the Duke Law Journal). 
pressed kind words for the IAHC plan, but it explained that the plan had "not [been] able to overcome" criticism of both its substance and the process by which it had been developed. ${ }^{104}$

On substantive matters, the White Paper backed away from its initial suggestions, and in particular from its proposal to implement five new top-level domains immediately. Noting the wide disparity of views reflected in the comments received in response to the Green Paper, the White Paper concluded that " $[\mathrm{t}]$ he challenge of deciding policy for the addition of new domains will be formidable" and left that task to the new corporation. ${ }^{10}$

The White Paper also backed away from any concrete suggestions regarding the structure of the new corporation. Recognizing that directors could not be elected immediately by subsidiary organizations that had not yet been formed, the White Paper placed new emphasis on the new corporation's "organizers," who would include "representatives of regional Internet number registries, Internet engineers and computer scientists, domain name registries, domain name registrars, commercial and noncommercial users, Internet service providers, international trademark holders, and Internet experts highly respected throughout the international Internet community," reflecting "substantial representation from around the world." These organizers, in order to get the new corporation going, would appoint an initial board of directors that was "broadly representative of the global internet community." 107 That initial board, in turn, would establish a system for electing subsequent directors. ${ }^{108}$

The White Paper was generally well received, in large part because it left all of the difficult policy questions to the new corporation. All of the various actors in the DNS debates were confident, or at least hopeful, that the new corporation, when it was formed, would see things their way.

\footnotetext{
104. White Paper, supra note 26, at 31,743.

105. Id. at 31,746 .

106. Id. at 31,749-50.

107. Id. at 31,750 . There was a good deal of argument later relating to the phrases "initial board" and "interim board" as applied to ICANN. As the relevant portion of the White Paper refers to the appointment "on an interim basis, [of] an initial Board of Directors (an interim Board)," $i d$., it seems plain that the Department of Commerce intended the phrases to be used interchangeably.

108. See id.
} 


\section{ICANN}

The White Paper did not speak precisely to how the new corporation it described would be formed. It suggested that if the new entity were formed by "private sector Internet stakeholders," the U.S. government was prepared to recognize it by entering into agreements with it, seeking international support for it, and ensuring that it had appropriate access to databases and software controlled by NSI. ${ }^{109}$ In October 1998, after a series of negotiations between IANA and NSI-and more wide-ranging consultations on the interim board's composition with the U.S. government, a variety of foreign governments, Jon Postel's lawyer (a Jones, Day partner named Joe Sims), IBM, and others ${ }^{110}$-Dr. Postel transmitted to the Department of Commerce documents reflecting what he described as "the consensus judgment of the global Internet community as to how to form a corporation that will include the IANA function." ${ }^{111}$ Those documents included the articles of incorporation of the new entity, which had already been incorporated in California as the Internet Corporation for Assigned Names and Numbers, or ICANN,${ }^{112}$ biographies of its initial board of directors, ${ }^{113}$ and a set of proposed bylaws. ${ }^{114}$ ICANN's initial directors were drawn, for the most part, from the worlds of telecommunications and information technology. ${ }^{115}$ Most of them were inno-

109. Id. at 31,749 .

110. See Letter from Ira C. Magaziner, Senior Advisor to the President for Policy Development, to Rep. Thomas J. Bliley, Jr., Chairman, United States House Committee on Commerce (Oct. 27, 1998) (on file with the Duke Law Journal).

111. Postel, supra note 1.

112. See Articles of Incorporation of Internet Corporation for Assigned Names and Numbers, National Telecommunications and Information Administration, at http://www.ntia.doc.gov/ ntiahome/domainname/proposals/icann/articles.htm (last visited Aug. 19, 2000) (on file with the Duke Law Journal).

113. See Biographies of Board of Directors, National Telecommunications and Information Administration, at http://www.ntia.doc.gov/ntiahome/domainname/proposals/icann/bios.htm (last visited Aug. 19, 2000) (on file with the Duke Law Journal).

114. See Bylaws for Internet Corporation for Assigned Names and Numbers, National Telecommunications and Information Administration, at http://www.ntia.doc.gov/ntiahome/ domainname/proposals/icann/bylaws.htm (last visited Aug. 19, 2000) (on file with the Duke Law Journal).

115. They were: Geraldine Capdeboscq, an officer of Bull, a France-based information technology company; George Conrades, formerly an officer of GTE Internetworking, BBN, and IBM; Greg Crew, Chairman of the Australian Communications Industry Forum; Esther Dyson, computer and Internet pundit; Frank Fitzsimmons, an officer of Dun \& Bradstreet; Hans Kraaijenbrink, Chair of the European Telecommunications Network Operators Association; Jun Murai, professor at Keio University (Japan); Eugenio Triana, formerly an official at the 
cent of any specialized knowledge of the Internet or of domain name issues. ${ }^{116}$ The idea was that the board members would be guided by the wisdom of Postel as the new corporation's chief technical officer and could lend their prestige and neutrality to bolster his decisions. ${ }^{117}$

ICANN was set adrift almost immediately when, a scant two weeks after delivering the corporate documents to the Department of Commerce, Jon Postel died of complications following open heart surgery. ${ }^{118}$ Yet for the Department of Commerce, it was too late to turn back. It solicited public comment on ICANN's proposal. ${ }^{119}$ It then detailed for ICANN a variety of respects in which Commerce felt that ICANN's proposed bylaws lacked adequate openness and accountability. ${ }^{120}$ After negotiations between Commerce and the new ICANN board, aggressively represented by Joe Sims, and a variety of changes to ICANN's proposed bylaws, Commerce and ICANN agreed on a memorandum of understanding. ${ }^{121}$ The memorandum recited that ICANN was "the organization that best demonstrated that it can accommodate the broad and diverse interest groups that make

European Commission and the Spanish Ministry of Industry and Energy; and Linda Wilson, President of Radcliffe College. See Biographies of Board Directors, supra note 113.

116. See Froomkin, supra note 34, at 73. The only board member who was expert in DNS issues was Jun Murai, who had also been a member of the IAHC. See Final Report, supra note 77.

117. See Froomkin, supra note 34, at 72.

118. See Kathleen Murphy, Death of Net Pioneer Postel Doesn't Stall Efforts to Strike Deal on New DNS Entity, INTERNET WORLD (Oct. 26, 1998), at http://www.findarticles.com/cf_0/ m0DXS/35_4/55361070/p1/article.jhtml (on file with the Duke Law Journal).

119. Those comments are archived at Comments on the Proposals for a New Corporation to Manage Internet Domain Name System Functions, National Telecommunications and Information Administration, at http://www.ntia.doc.gov/ntiahome/domainname/proposals/comments/ comments.html (Sept. 30-Oct. 15, 1998) (on file with the Duke Law Journal).

120. See Letter from J. Beckwith Burr, Associate Administrator (Acting), National Telecommunications and Information Administration, to Herb Schorr, Executive Director, USC Information Sciences Institute (Oct. 20, 1998), National Telecommunications and Information Administration, http://www.ntia.doc.gov/ntiahome/press/icann102098.htm (on file with the Duke Law Journal).

121. See Memorandum of Understanding Between the U.S. Department of Commerce and Internet Corporation for Assigned Names and Numbers, National Telecommunications and Information Administration, at http://www.ntia.doc.gov/ntiahome/domainname/icannmemorandum.htm (last visited Aug. 18, 2000) (on file with the Duke Law Journal) [hereinafter Memorandum of Understanding]; see also Declan McCullagh, Magaziner: ICANN, Mend Thy Ways, WIRED NeWs (Nov. 18, 1998) (describing some of the public statements that accompanied the negotiations), at http://www.wired.com/news/politics/0,1283,16356,00.html (on file with the Duke Law Journal); Ellen Rony, Comparison of Bylaws Proposals for a New Internet Corporation, at http://www.domainhandbook.com/comp-bylaws.html (last modified Nov. 24, 1998) (comparing various bylaws proposals floated during this period) (on file with the Duke Law Journal). 
up the Internet community." ${ }^{, 22}$ ICANN and Commerce would jointly design, develop, and test mechanisms, methods, and procedures for DNS management, and they would formulate the steps necessary to transition DNS management responsibility to a nonprofit corporation. ${ }^{123}$ Once those mechanisms were tested and found adequate, "it [was] contemplated that management of the DNS [would] be transitioned." "24 Together, the memorandum pledged, "the Parties [would] collaborate ... to achieve the transition without disruption." 125

Three months later, Commerce notified NSI that it was designating ICANN as the new corporation described in the White Paper for purposes of the U.S. government's cooperative agreement with NSI. ${ }^{126}$ This meant that NSI was required to acknowledge ICANN's authority to carry out the responsibilities of the new corporation as described in the White Paper. ${ }^{127}$ The cooperative agreement contemplated that as the U.S. government shifted domain name management responsibilities to ICANN, NSI's corresponding obligations under that agreement would be terminated, and, as appropriate, covered in a contract between NSI and ICANN. ${ }^{128}$ The U.S. government, on the other hand, was not letting go of the reins just yet; ICANN's designation did not change the fact that, at least for the time being, NSI was

122. Memorandum of Understanding, supra note 121.
123. See id.
124. Id.
125. Id.
126. See Letter from J. Beckwith Burr, Associate Administrator (Acting), National Teletions, Inc. (Feb. 26, 1999), National Telecommunications and Information Administration, http://www.ntia.doc.gov/ntiahome/domainname/icannnewco.htm (on file with the Duke Law Journal). In September 1998, the Department of Commerce had replaced the National Science Foundation as the U.S. government entity administering the cooperative agreement. See Letter from John Sopko, Chief Counsel for Special Matters, Department of Commerce, to Rep. Thomas J. Bliley, Jr., Chairman, United States House Committee on Commerce (Nov. 5, 1998) (attaching Memorandum of Agreement between the National Science Foundation and the U.S. Department of Commerce) (on file with the Duke Law Journal).

127. NSI had agreed, in June of 1998 , that

[a]s provided in the [White Paper], the USG will effect the transition of its DNS responsibilities through an agreement with NewCo.... Following the finalization of the agreement between the USG and NewCo, NSI will recognize NewCo pursuant to a contract between NSI and NewCo. NSI acknowledges that NewCo will have the authority, consistent with the provisions of the [White Paper] and the agreement between the USG and NewCo, to carry out NewCo's Responsibilities.

Amendment 11, supra note 92.

128. See id. (indicating the contract details in the "Term and Transition" clause). 
prohibited from "making or rejecting any modifications, additions, or deletions to the root zone file" without written direction from an authorized U.S. government official. ${ }^{129}$

The ICANN experiment was underway.

\section{THE PROBLEM OF LEGITIMACY}

Notwithstanding that ICANN had received the blessing of the U.S. government, its public legitimacy was open to serious challenge. Its board members had been chosen in a closed process, the details of which are still unclear. ${ }^{130}$ The board's early penchant for closed meetings intensified the air of secrecy surrounding the new organization; the Internet community knew neither who these people were nor how they were reaching their decisions. ${ }^{131}$ Many of the board members, further, were unfamiliar with Internet technical issues and Internet mores. ${ }^{132}$ They were slow to embrace openness and communication; for the most part, ICANN communicated to the outside world

129. See Amendment 11, supra note 92 ("While NSI continues to operate the primary root server, it shall request written direction from an authorized USG [United States Government] official before making or rejecting any modifications, additions or deletions to the root zone file.").

130. The General Accounting Office recently issued a report in which it concluded that the interim board was selected primarily by Jon Postel. See GAO Report, supra note 24, at 13 (providing the GAO's analysis). As evidence supporting its conclusion, the GAO report cited Dr. Postel's testimony and ICANN's own statements. See id. at 13-14. The GAO's primary concern in this aspect of its investigation related to whether the Department of Commerce had effectively selected ICANN's board. See id. at 12-14 (inquiring into the board's selection in the context of its conclusion that the Government Corporation Control Act, 31 U.S.C. § 9102, applied only if the Department had "establish[ed]" ICANN).

131. See Courtney Macavinta, ICANN Defensive in Letter to Commerce, CNET NEWs (July 9, 1999) (noting criticisms by Rep. Bliley and the Commerce Department of ICANN secrecy), at http://news.cnet.com/news/0-1005-200-344631.html?tag=st.ne.1.srchres.ni (on file with the Duke Law Journal); Courtney Macavinta, New Domain Group Faces Critics, CNET NEws (Nov. 15, 1998) (noting distrust of ICANN stemming from the secrecy surrounding the selection of ICANN's board), at http://news.cnet.com/news/0-1005-200-335384.html?tag=st.ne.1.srchres.ni (on file with the Duke Law Journal); Murphy, supra note 118. The identity of the board members, of course, was not kept secret, but most of the board members were not familiar figures in the DNS community. See Froomkin, supra note 34, at 72-73; supra notes $115-17$ and accompanying text.

132. The board members, for the most part, had telecommunications and information technology backgrounds. See supra notes 115-17 and accompanying text. Although some-most notably Esther Dyson and Jun Murai-were well-steeped in Internet culture, others were rather less deeply familiar with it and with the relevant technology. 
through its public relations firm ${ }^{133}$ and its lawyers. ${ }^{134}$ All of this was massively problematic for an organization that sought control over Internet infrastructure as an organ of the Internet technical community. ${ }^{135}$ Because the U.S. government's authority over the DNS was murky, ICANN could not derive legitimacy from its designation by the government as the entity assigned to perform both ministerial and policymaking DNS functions. There were many in the Internet community who asserted that ICANN was simply illegitimate-that it had no right to the role it sought. ${ }^{136}$

The legitimacy issue was important because the Department of Commerce's recognition as such gave ICANN little in the way of actual legal authority. The U.S. government, after all, had never managed the DNS through command-and-control regulation, and it had no command-and-control authority to delegate. ${ }^{137}$ ICANN was in a position to control other DNS actors only by entering into contracts in which those actors agreed to be bound.

Some DNS actors were eager to contract with ICANN. Aspiring registrars for .com, .net, and .org had every incentive to submit to the ICANN accreditation process, because that was the only way they could take advantage of an agreement between Commerce and NSI that compelled NSI to open its registration system to new, competing registrars.

133. See ICANN Announces International Education and Public Outreach Support in Collaboration with Alexander Ogilvy, at http://www.icann.org/announcements/icann-pr03feb99-2. htm. (Feb. 3, 1999) (on file with the Duke Law Journal).

134. See Domain Name System Privatization, supra note 7, at 155 (testimony of Prof. Jonathan Weinberg); see also Ted Byfield, UDRP? JDRP., Tasty Bits from the Technology Front, at http://www.tbtf.com/roving_reporter/jdrp.html (Nov. 16, 1999) (explaining that it has been ICANN's lawyers, more than anyone else, who have defined its course) (on file with the Duke Law Journal). For an important early ICANN statement whose language strongly suggests that it was written by ICANN's lawyers, see ICANN-Response to Chairman Bliley, at http://www.icann.org/correspondence/bliley-response-08july99.htm (July 8, 1999) (on file with the Duke Law Journal) [hereinafter ICANN's Response]. With the notable exception of Esther Dyson and (to some degree) CEO Mike Roberts, ICANN's directors did not discuss DNS issues on electronic mailing lists open to outsiders.

135. See Domain Name System Privatization, supra note 7, at 155 (testimony of Prof. Jonathan Weinberg).

136. See, e.g., Patrick Greenwell, Despite Our Best Efforts, ICANN Fails in Many Respects, at http://www.icannwatch.org/archives/essays/944584730.shtml (Dec. 7, 1999) (listing ICANN inadequacies and failures) (on file with the Duke Law Journal).

137. See supra note 92 and accompanying text. 
NSI was reluctant to recognize ICANN (which it correctly saw as a threat to its autonomy), but the Department of Commerce ${ }^{138}$ was in a position to assist ICANN with that relationship. The Department of Commerce had already succeeded in negotiating an amendment to its cooperative agreement with NSI directing NSI to recognize ICANN's authority, ${ }^{139}$ and it was pressuring NSI to enter into a contract with ICANN that would bind it to follow ICANN's directives. ${ }^{140}$ The U.S. government's leverage was the possibility that, on expiration or termination of the cooperative agreement, it could seek to divest NSI of its position as registry for .com, .net, and .org. ${ }^{141}$

The U.S. government's relationship with NSI, indeed, was the key source of ICANN's authority, because NSI operated the "A" root server subject to U.S. government instructions. ${ }^{142}$ ICANN was looking forward to the day the U.S. government would terminate the contractual provisions giving it authority over the root and transfer that

138. The Department of Commerce had taken the point position for the U.S. government on domain name policy when it issued the Green Paper in January 1998. It had replaced the National Science Foundation as the U.S. government entity administering the NSI cooperative agreement in September 1998, see supra note 126, signed the Memorandum of Understanding with ICANN in November 1998, see supra note 121 and accompanying text, and would enter into a contract with ICANN for the performance of the functions previously contracted for by the Defense Department in February 2000. See Contract Between ICANN and the United States Government for Performance of the IANA Function, at http://www.icann.org/general/ianacontract-09feb00.htm (Feb. 9, 2000) (on file with the Duke Law Journal).

139. In June 1998, Commerce and NSI had negotiated an amendment to the cooperative agreement under which NSI agreed that the U.S. government would designate a new entity, then referred to only as "NewCo," to take over the U.S. government's DNS responsibilities. NSI promised to recognize NewCo, to enter into a contract with it, and to acknowledge its authority to carry out its responsibilities under the White Paper. In February 1999, Commerce notified NSI that it was designating ICANN as "NewCo" for purposes of the cooperative agreement. See supra note 127 and accompanying text.

140. NSI and ICANN entered into such a contract in November 1999, after arduous, threeway negotiations among ICANN, NSI, and the Department of Commerce. See Approved Agreements Among ICANN, the U.S. Department of Commerce, and Network Solutions, Inc., at http://www.icann.org/nsi/nsi-agreements.htm (Nov. 10, 1999) (on file with the Duke Law Journal) [hereinafter Approved Agreements].

141. See Pincus, supra note 65. Commerce also put effort into persuading other domain name actors, including the root server operators, to enter into contracts with ICANN. The Department of Commerce and ICANN have entered into a Cooperative Research and Development Agreement to collaborate on issues including "formalization of contractual relationships under which root servers throughout the world are operated." Cooperative Research \& Development Agreement, at http://www.icann.org/committees/dns-root/crada.htm (last visited Aug. 24, 2000) (on file with the Duke Law Journal).

142. See supra note 64 and accompanying text. 
authority to ICANN. At that point, ICANN would have sole control over the contents of the "A" root. ${ }^{143}$

Yet ICANN's consolidation of control was hardly assured. The root server operators, who historically had no formal relationship with IANA, had no obvious incentive to enter into contracts with ICANN now. The operators of the country code top-level domains similarly had a great deal of bargaining power in negotiating any new arrangements with ICANN. Although ICANN, as proprietor of the root, could threaten to delete any country code top-level domain registries that declined to sign an agreement, the threat would be an empty one. The U.S. government would hardly approve wholesale deletions from the root. More importantly, there would be no better way for ICANN to destroy its own legitimacy than for it arbitrarily to manipulate the root zone file to enhance its own power. In a worstcase analysis, governments, Internet service providers, or major institutional users could establish a consortium of alternative root servers outside of ICANN's control. To the extent that users decided they should no longer direct their DNS queries in the direction of the legacy root, the contents of the ICANN-controlled root zone file would be irrelevant.

ICANN's legitimacy was important, in short, because failure to be perceived as an appropriate wielder of DNS authority could have left it unable to exercise that authority. This point bears repeating: ICANN started its life with some key advantages. The support of the U.S. government and the terms of the government's agreements with NSI meant that ICANN had the support of the registrars, had a superior position in its negotiations with NSI, and was on track to gain control of the "A" root. ICANN could not succeed, however, unless it could consolidate its position by entering into agreements with other Internet actors, and it could not enter into those agreements unless it was seen by the Internet community as an appropriate and legitimate entity to supervise the DNS. To the extent that its legitimacy was less secure, ICANN would be forced to concede greater autonomy to other actors. If its legitimacy collapsed entirely, it might see large segments of the community defecting to alternative root systems.

ICANN's task in seeking public acceptance of its legitimacy was made more complicated by the fact that it was a private entity seeking to play the sort of role more commonly played in our society by pub-

143. See supra notes $126-28$ and accompanying text. 
lic entities. Its self-assigned task, after all, was one of setting rules for an international communications medium of surpassing importance. The task, administration of Internet identifiers, had historically been performed at the behest of the U.S. government and had been conducted in an explicitly public-regarding manner.

Although both the U.S. government and ICANN itself consistently described its role as mere "technical management," it seemed clear that ICANN was making important public policy choices. ${ }^{144}$ Whether and how to add new top-level domains was in essential respects a policy issue, not a technical one..$^{145}$ Indeed, the issue that consumed ICANN soon after its creation was the question of structures under which trademark holders could gain control of second-level domain names that were similar to their trademarks. ${ }^{146}$ It is hard, by any stretch of the imagination, to characterize this issue as one of Internet "technical management."

Finally, ICANN's contract-based policy implementation looked uncannily like command-and-control regulation. The plainest example relates to ICANN's imposition of the Uniform Dispute Resolution Procedure, or UDRP. Under the UDRP, each domain registrant in the generic top-level domain is subject to a mandatory administrative procedure in which an arbitrator can order the domain name transferred to a complaining trademark owner if it finds that certain factual conditions are met. ${ }^{147}$ The UDRP was implemented by contractual means. In order to receive ICANN accreditation, registrars had to agree that they would include terms imposing the UDRP in the contracts they made available to would-be domain name regis-

144. See David Post, Governing Cyberspace, at http://www.icannwatch.org/archives/essays/ 930604982.shtml (June 6, 1999) (explaining that ICANN's activities were "already way beyond the realm of technical "standards-setting," and involved "global Internet policy") (on file with the Duke Law Journal).

145. The lengthy discussion in ICANN's Working Group C on the addition of new generic top-level domains focused almost entirely on policy, rather than technical, issues. See Interim Report of Working Group C of the Domain Name Supporting Organization, Domain Name Supporting Organization, at http://www.dnso.org/dnso/notes/19991023.NCwgc-report.html (Oct. 23,1999 ) (on file with the Duke Law Journal).

146. See Uniform Domain Name Dispute Resolution Policy, at http://www.icann.org/udrp/ udrp-policy-24oct99.htm (Oct. 24, 1999) (establishing a mechanism through which trademark holders can gain control of second-level domain names that are identical or confusingly similar to their trademarks, if the domain name holder has no rights or legitimate interests in the name and registered and is using it in bad faith) (on file with the Duke Law Journal) [hereinafter $U D R P]$.

147. See id. 
trants. ${ }^{148}$ Moving away from legal form, the substance of the requirement was that all persons registering Internet domain names outside of the country code top-level domains were required to submit themselves to this procedure. ICANN, in short, was both asserting control over the design of the name space and imposing constraints on people using that space.

ICANN's exercise of authority looked, walked, and quacked like public regulatory power. This raised a crucial hurdle for ICANN to surmount in any quest for public legitimacy: Was its exercise of this power consistent with our usual thinking about public power and public policymaking? American political philosophy is built around a public-private distinction in which private actors presumptively have control over their own resources, but it is problematic for them to control public resources. A private entity wielding what amounts to public power may be subjected to constitutional restraints designed to ensure that its power is exercised consistently with democratic values. ${ }^{149}$ This issue resonates in politics and public policy as well as law: ICANN was unlikely to win public acceptance in democratic nations if it could not answer the charge that it was exercising policymaking authority in a way inconsistent with core democratic values.

\section{LEGITIMACY AND ADMINISTRATIVE LAW}

In the rest of this Article, I shall address ICANN's responses to the legitimacy questions I raised in the previous section. What made ICANN an appropriate entity to be the central decisionmaker for the domain name and IP number systems? ICANN was seeking to insert itself at the apex of a decisionmaking structure so that it could say (among other things) which top-level domains would exist, what the economic structure of registration in the top-level domains would be, who would control those portions of the name space, what special rights (beyond the protections granted by ordinary legislation and en-

148. The ICANN registrar accreditation agreement binds each registrar to adhere to any "policy or procedure [adopted by ICANN] for resolution of disputes concerning SLD names." Registrar Accreditation Agreement, at http://www.icann.org/nsi/icann-raa-04nov99.htm\#IIK (Nov. 4, 1999) (on file with the Duke Law Journal). The ICANN-prescribed UDRP terms, to be included in every domain name registrant's contract, can be found at UDRP, supra note 146.

149. See, e.g., Evans v. Newton, 382 U.S. 296, 301 (1966) (holding that a privately-owned park was subject to equal protection limitations because the park was effectively a public facility, municipal in character, and the city was "entwined" in its control); Marsh v. Alabama, 326 U.S. 501, 509 (1946) (holding that a company-owned town's rules forbidding religious solicitations were subject to First Amendment limitations). 
forced by national courts) trademark owners would be able to assert against other domain name registrants, and how blocks of IP addresses would be allocated. ${ }^{150}$ Yet the ICANN board members were, in crucial respect, self-appointed. ${ }^{151}$ They needed to explain why they, of all people, should be trusted with this authority. ${ }^{152}$ Moreover, they needed to explain why-to the extent that ICANN was exercising what looked a lot like public regulatory power-the Internet community should view its exercise of that power as consistent with its understanding of how such powers should be checked and cabined.

In assessing ICANN's answers to those questions, it is instructive to note the parallels between the questions ICANN faced and a set of similar questions addressed, historically, to the United States administrative agency. ICANN's legitimacy concerns, to be sure, were crucially different from those faced by the administrative agency, because the federal agency had answers to its legitimacy questions that ICANN could not provide. In answer to the question "who gave you the right to make public policy," the federal agency could point to a grant of power in a statute enacted by Congress and to the fact that the President had nominated (and the Senate confirmed) the agency's top administrators. Yet the federal agency, throughout its history, has also faced legitimacy objections, and those objections bear illuminating parallels to the objections facing ICANN today.

The legitimacy crisis of the federal agency lay in the fact that agencies create public policy and exercise public power-they make decisions imposing legal obligations, and otherwise changing legal relationships, in ways that directly affect us all-notwithstanding questionable democratic credentials and no direct political accountability. ${ }^{153}$ Administrative agencies, after all, are run by folks who are not elected by, and are not accountable to, the people. Although agency heads are appointed by elected officials, they are not them-

150. See ICANN Yokohama Meeting Topic: Introduction of New Top-Level Domains, at http://www.icann.org/yokohama/new-tld-topic.htm (June 13, 2000) (addressing all of these issues except for IP address allocation) (on file with the Duke Law Journal); White Paper, supra note 26, at 31,749 (noting that ICANN should set policy for allocation of IP number blocks to regional Internet number registries).

151. See supra note 109-14 and accompanying text.

152. Again, because the U.S. government's own authority over the DNS was clouded, the mere fact that the U.S. government had recognized ICANN did not establish ICANN's legitimacy. See supra notes 122-28 and accompanying text.

153. See John Hart Ely, Democracy AND Distrust 132 (1980) (explaining that only elected legislators, unlike unelected bureaucrats, are subject to "the sort of accountability that is crucial to the intelligible functioning of a democratic republic"). 
selves elected. ${ }^{154}$ They are not especially visible, and often only specialists even know who they are. If I am unhappy with the policy choices of an administrative agency, I have no way to "throw the bums out" except by voting out an entire presidential administration-a blunt instrument if there ever were one. Nor do agency members share the courts' legitimacy assurances-a public commitment to neutral, principled decisionmaking, insulation from political pressure, and life tenure. ${ }^{155}$

Accompanying agencies' insulation from direct democratic control is the fact that agencies often appear to have tremendously broad policy autonomy. Their enabling statutes frequently provide only the vaguest of policy guidelines. ${ }^{156}$ Congress's ability to supervise what some view as the agencies' "unavoidably expanding power" is limited, ${ }^{157}$ and the President himself has only limited policy authority over many agencies. ${ }^{158}$

The combination of these two factors raises persistent concerns in administrative law and administrative law scholarship relating to agency legitimacy-how can we reconcile broad agency policymaking discretion with the agency's insulation from democratic control? ${ }^{159}$ More than anything else, administrative law represents an attempt to resolve that question. ${ }^{160}$ "[A]dministrative law has been defined by the crisis of legitimacy and the problem of agency discretion,"

154. See, e.g., 47 U.S.C. $§ 154$ (1994) (providing that FCC Commissioners are appointed by the President, with the advice and consent of the Senate).

155. See Stephen Breyer et Al., Administrative LaW ANd Regulatory Policy 146 (4th ed. 1999).

156. See, e.g., 47 U.S.C. $§ 307$ (a) (1994) (directing the FCC to grant broadcast licenses "if public convenience, interest, or necessity will be served thereby"); FCC v. RCA Communications, Inc., 346 U.S. 86, 91 (1953) (describing Communications Act guidelines as "the vaguish, penumbral bounds expressed by the standard of 'public interest'").

157. INS v. Chadha, 462 U.S. 919, 1002 (1983) (White, J., dissenting). But see Barry R. Weingast \& Mark J. Moran, The Myth of Runaway Bureaucracy-The Case of the FTC, 6 REgUlation, May/June 1982, at 33, 37 (concluding that Congress has substantial ongoing influence over regulatory policy, albeit via "subtle and indirect" means).

158. See generally Symposium, The Independence of Independent Agencies, 1988 DUKE L.J. 215 (collecting perspectives on the "independence" of independent agencies).

159. As John Hart Ely put the concern: "There can be little point in worrying about the distribution of the franchise and other personal political rights unless the important policy choices are being made by elected officials." ELY, supra note 153, at 133.

160. See Jerry L. Mashaw et Al., Administrative Law: The American Public Law SYSTEM 37-41 (4th ed. 1998).

161. Jody Freeman, The Private Role in Public Governance, 75 N.Y.U. L. REV. 543, 545 (2000); see also BREYER ET AL., supra note 155, at 146 ("It is sometimes said that the administrative process in the United States suffers from a near-perpetual crisis of legitimacy ...."). 
turn, "administrative law scholarship has organized itself largely around the need to defend the administrative state against accusations of illegitimacy." ${ }^{162}$ The debate has been as much one of politics and of public policy as of law. Its battleground has been not merely judicial review, but also public acceptance of administrative authority. ${ }^{163}$

Administrative law thinking has found a variety of responses to the "problem of discretion." Perhaps the first was a denial that agencies did make policy. This approach saw the agency, in Professor Richard Stewart's famous phrase, as no more than a "transmission belt for implementing legislative directives." ${ }^{164}$ In a key early case, thus, the Supreme Court approved the creation of an independent agency whose members served for fixed terms, and were to that degree insulated from presidential policy guidance, on the theory that the agency enforced "no policy except the policy of the law." ${ }^{165}$ This administrative law model saw agencies as machine-like: they were purely instrumental in function, incapable of exercising threatening discretion because they merely responded mechanically to their legislative principals' commands, and yet too technical and complex to be tinkered with by laymen. ${ }^{166}$ At most, the argument ran, the role of the agency was to apply neutral technical expertise in ascertaining the objective public interest. ${ }^{167}$

That response, though, could not long stay credible. It had become too clear, for too long, that agencies routinely make policy decisions. It would have been fruitless, for example, to argue that the Federal Communications Commission did not make policy whenwith only the words "public interest, convenience and necessity" to guide it - it established rules forbidding a firm from owning broadcast stations and daily newspapers in the same market and proscribing particular terms in network affiliation contracts. ${ }^{168}$ Rather, at the core

162. Freeman, supra note 161 , at 546 .

163. See generally Timothy H. Jones, Administrative Law, Regulation, and Legitimacy, 16 J.L. \& SOC'Y 410 (1989) (analyzing regulatory programs through different models of legitimacy).

164. Richard B. Stewart, The Reformation of American Administrative Law, 88 HARV. L. REV. 1669, 1675 (1975).

165. Humphrey's Ex'r v. United States, 295 U.S. 602, 624 (1935).

166. See Gerald E. Frug, The Ideology of Bureaucracy in American Law, 97 HARV. L. REV. 1276, 1297-98 (1984).

167. See BREYER ET AL., supra note 155, at 146-47.

168. See FCC v. National Citizens Comm. for Broad., 436 U.S. 775, 796-97 (1978) (sustaining an FCC regulation barring the acquisition by a broadcast station of a daily newspaper in the 
of the agency's legitimacy crisis is the fact that it is the agency's job to exercise independent public policy discretion. ${ }^{169}$ The task of administrative law, then, becomes one of explaining how to reconcile that policymaking discretion with the democratic project.

Administrative law thinking has generated at least three important defenses of agency legitimacy. ${ }^{170}$ The first set corresponds to the approach that Professor Stewart termed the "traditional" model. ${ }^{171}$ In this model, agencies' policymaking discretion is acceptable because it is constrained by two sets of legal rules. First, agencies must stay within the bounds of their statutory delegations. Judicial review is available to enforce that limitation. ${ }^{172}$ Second, agency discretion is constrained by requirements of fair process and reasoned decisionmaking. ${ }^{173}$ Agencies engaged in legislative rulemaking must solicit

same market, or vice versa, and requiring divestiture of some newspaper-broadcast combinations); National Broad. Co. v. United States, 319 U.S. 190, 224-27 (1943) (upholding FCC regulation of network affiliation contracts); supra note 156; see also David Epstein \& Sharyn O'Halloran, The Nondelegation Doctrine and the Separation of Powers: A Political Science Approach, 20 CARDOZO L. REV. 947, 948 (1999) (noting that executive agencies are often "given real policymaking discretion in their own right, with either no statutory guidance or guidance that is so broad that it imposes almost no constraints on executive actions"); Stewart, supra note 164, at 1711-12 ("[A]dministrative law theories that treat agencies as mere executors of legislative directives are no longer convincing.").

169. Professor Stewart noted:

The "transmission belt" fails because broad legislative directives will rarely dispose of particular cases once the relevant facts have been accurately ascertained. More frequently, the application of legislative directives requires the agency to reweigh and reconcile the often nebulous or conflicting policies behind the directives in the context of a particular factual situation with a particular constellation of affected interests. The required balancing of policies is an inherently discretionary, ultimately political procedure.

Stewart, supra note 164 , at 1684 .

170. These three models are heuristic tools; they are broad and oversimplified. My offering, further, is only one possible way of slicing and dicing the range of theories that have been offered to explain, and justify, the administrative state. For a somewhat different underlying structure, see Gerald Frug's magisterial work in Frug, supra note 166, at 1282-84 (proposing the formalist model, the expertise model, the judicial review model, and the market/pluralist model as four "models of bureaucratic legitimacy").

171. See Stewart, supra note 164, at 1671-76. In Professor Frug's typology, this corresponds most closely to the "judicial review" model. See Frug, supra note 166, at 1334-55.

172. See Stewart, supra note 164, at 1673-74.

173. See MASHAW ET AL., supra note 160, at 39. Within the bounds of searching process and rationality review, American judges debated whether courts should emphasize agency adherence to a fair and open decisionmaking process or substantive oversight of agency decisions for arbitrariness and irrationality. Compare, e.g., Ethyl Corp. v. EPA, 541 F.2d 1, 66-67 (D.C. Cir. 1976) (Bazelon, J., concurring) (urging that judges should limit their review of highly technical agency decisions to ensuring that the decisionmaking process follows proper procedural safeguards), with id. at 68-69 (Leventhal, J., concurring) (countering that judges must acquire 
public comment and consider carefully the issues raised, rationally justifying each policy choice. ${ }^{174}$ Agencies must attend to the public's views not for the sake of democratic values, but because bureaucratic rationality requires the informed consideration of a broad range of alternatives, and public comment is necessary to provide the data and perspectives that the agency would otherwise lack. ${ }^{175}$ Once again, it is the job of the courts to enforce those procedural norms. ${ }^{176}$

A second set of answers to the problem of discretion corresponds to the model Professor Stewart termed "interest representation."177 Here, the focus is on a different aspect of process-fair representation for all affected interests within the ranks of those with access to agency decisionmakers. ${ }^{178}$ The answer to the problem of discretion is found not in bureaucratic rationality enforced by the courts, but in the pluralist political process as reproduced within the agency itself. ${ }^{179}$ Agency decisionmakers must consider the wishes of all relevant groups so that their decisions will resemble those that would be made by the people themselves. ${ }^{180}$

A third set of answers arises from the conviction that neither the traditional norms of procedural regularity and bureaucratic rationality nor an agency-centered interest representation provide adequate answers for the ills facing agencies today. The constant requests today

enough of a technical background to provide substantive review of agency decisions and ensure that the decisions are reasonable).

174. See, e.g., 5 U.S.C. § 553(c) (1994) (requiring agencies to "give interested persons an opportunity to participate in the rule making through submission of written data, views, or arguments"); Motor Vehicles Mfrs. Ass'n v. State Farm Mut. Ins. Co., 463 U.S. 29, 48 (1983) (requiring agencies to supply reasoned analysis explaining their rejection of plausible alternative courses of action); see also Jonathan Weinberg, Broadcasting and the Administrative Process in Japan and the United States, 39 BUFF. L. REV. 615, 629 (1991) (describing the demands of formal rationality).

175. Mashaw, Merrill, and Shane suggest that under a philosophy of liberal legality, agencies were required to provide open proceedings and opportunity for public participation in order to ensure due process and adequate judicial review. Later on, the same procedural mechanisms were seen as promoting a pluralist political accommodation because they enabled all affected interests to have their views considered in the agency process. See MASHAW ET AL., supra note 160, at 40-41. My emphasis here, though, is on the contribution that participatory mechanisms make to the substantive decision rationality that is central to the traditional model.

176. See Louis JafFe, Judicial Control of Administrative ACtion 320-21 (1965) (stating that "the availability of judicial review is, in our system and under our tradition, the necessary premise of legal validity").

177. Stewart, supra note 164 , at 1722.

178. See id. at 1712 .

179. See id.

180. See, e.g., Frug, supra note 166, at 1360. 
for review of agency decisions, lawyers and academics have argued, demonstrate that the agency process has lost legitimacy. Rather than the agency reaching decisions and imposing them on industry members, the agency should, wherever possible, become a forum in which the interests that will be affected by a given decision can negotiate directly and reach their own consensus, a consensus the agency can then ratify. ${ }^{181}$

ICANN has drawn on all three of these philosophical strands in fashioning tools and structures to address its own crisis of legitimacy. To begin with, ICANN has insisted that its activities are mere "technical coordination" or "technical management" of the domain name and IP address system. ${ }^{182}$ Such Internet technical management,

181. See, e.g., Jody Freeman, Collaborative Governance in the Administrative State, 45 UCLA L. REV. 1, 21-22 (1997) (describing "collaborative governance" as a means of reorienting regulatory procedures around "joint problem solving and away from controlling discretion"); Philip J. Harter, Negotiating Regulations: A Cure for Malaise, 71 GEO. L.J. 1 passim (1982) (urging that agencies formulate rules through a process of negotiation among affected interests); Lawrence Susskind \& Gerard McMahon, The Theory and Practice of Negotiated Rulemaking, 3 YALE J. REG. 133, 136 (1985-86) ("The current rulemaking process is bound to generate dissatisfaction as long as regulatory agencies retain the exclusive responsibility for making the technical judgments and political compromises needed to develop a rule."). For a skeptical view, see William Funk, When Smoke Gets in Your Eyes: Regulatory Negotiation and the Public Interest, 18 ENVTL. L. 55, 57 (1987) (concluding that "the nature of regulatory negotiation has the tendency to obscure, if not pervert, the public interest to the benefit of private interests"). The reader should not confuse this sort of regulatory negotiation with negotiated agreement in the drafting of statutes. See generally Jessica Litman, Copyright, Compromise, and Legislative History, 72 CORNELL L. REV. 857 (1987) (chronicling negotiations among affected parties in the drafting of the 1976 Copyright Act); Jessica Litman, Copyright Legislation and Technological Change, 68 OR. L. REV. 275, 323-57 (1989) (examining the effects of negotiated agreements in twentieth-century U.S. copyright legislation). Negotiated statutes are often problematic from a policy standpoint, owing in part to the difficulty of representing all potentially affected interests. See generally JESSICA LiTMAN, DigitAl COPYRIGHT (forthcoming March 2001). They are less problematic legally than their regulatory counterparts, however, because Congress-unlike the agency-is subject to neither process transparency nor formal rationality requirements.

182. ICANN describes itself as "a technical coordination body for the Internet." ICANN Home Page, at http://www.icann.org (last visited Sept. 7, 2000) (on file with the Duke Law Jour$n a l)$. Its chair has described its task as "oversight of a select set of key technical administrative functions." Letter from Esther Dyson, Interim Chairman, ICANN, to Rep. Thomas J. Bliley, Jr., Chairman, United States House Committee on Commerce (July 8, 1999), http://www.icann.org/correspondence/dyson-letter-08july99.htm (on file with the Duke Law Journal). At ICANN's public forum on March 9, 2000, ICANN board member Hans Kraaijenbrink remarked, as paraphrased in the scribe's notes: "[The] [m]ission of ICANN is the technical coordination of certain essential parameters for the Internet names and addresses, nothing more, nothing less. Anyone who says it is more is confusing the Internet community." Scribe's Notes, ICANN Public Forum, Berkman Center for Internet and Society, at http://cyber.law.harvard.edu/icann/cairo/archive/scribe-icann-030900.html (Mar. 9, 2000) (on file with the Duke Law Journal). A recent ICANN presentation concedes that ICANN's "technical coordination of unique values sometimes requires accounting for non-technical policy interests" 
ICANN's defenders have urged, has historically been in the hands of those with technical expertise and should not be seen as raising larger policy issues. ${ }^{183}$ This argument is untenable. ICANN's key activities have involved policy choices rather than matters of technical detail. It is hard to argue, for example, that the development of protections for trademark owners against confusingly similar domain names is a matter without public policy implications. ${ }^{184}$ Most of the issues raised by the addition of new generic top-level domains are not within the primary jurisdiction of the network engineer; they raise larger policy questions. Indeed, ICANN as it is currently constituted is not unusually rich in technical expertise. ${ }^{18}$

So ICANN, like the federal administrative agency, has retreated to fallback arguments. First, it has invoked what one might call the techniques of administrative law: it has, in important respects, structured itself so that it looks like a classic U.S. administrative agency using, and bound by, the tools of bureaucratic rationality. ${ }^{186}$ Second, ICANN has invoked the techniques of representation: it has adopted structures and procedures that make it look more nearly like a repre-

such as data privacy, trademark, and competition. Andrew McLaughlin, ICANN Presentation to U.S. Chamber of Commerce, Washington, D.C., slide 27, at http://www.icann.org/ presentations/uscoc-ajm.ppt (June 20, 2000) (on file with the Duke Law Journal).

183. Joe Sims (who had been Jon Postel's lawyer, became ICANN's outside counsel, and was hugely influential in ICANN's formation) thus pointed out that historically, the Internet was managed and made to function by the engineering community and was financed largely by private businesses. See Joe Sims, Response to Froomkin, at http://www.icann.org/commentsmail/comment-bylaws/msg00025.html (Oct. 23, 1999) (on file with the Duke Law Journal). There was no reason, he continued, why the public should have a role in its governance. See id. Indeed, he urged, ICANN's task is the "development of policies that will promote the continued stable operation of the DNS." Id. This requires "consideration of technical issues that are generally not accessible to ... the user community as a whole." Id.

184. See supra notes $144-46$ and accompanying text.

185. On the meager technical backgrounds of the initial ICANN board members, see supra notes 115-16 and accompanying text. Several of them, perhaps a majority, were not aware of the domain name wars or that an organization like ICANN was being created until they were asked to serve on its board. See ICANN's Response, supra note 134. To be fair, the nine additional members who have been added to the board as of this writing have considerably more technical knowledge than the initial members: six of them have Internet technical backgrounds, while two are legally trained, and one is from the world of telecommunications. See About ICANN, at http://www.icann.org/general/abouticann.htm (Sept. 5, 2000) (providing biographies of the board members) (on file with the Duke Law Journal). Of ICANN's three key policymaking staff members, one (CEO Michael Roberts) is technically trained, and two (Chief Policy Officer Andrew McLaughlin and Vice-President and General Counsel Louis Touton) are lawyers. See $i d$.

186. See infra Part IV.A. 
sentative (that is to say, an elective) government body. ${ }^{187}$ Finally, it has invoked the techniques of consensus: it has asserted that it derives its authority from its ability to manifest the consensus of the larger community through discussion. ${ }^{188}$

In the rest of this Article, I shall try to describe what ICANN has done under each of these three headings and to assess whether it has succeeded. My test of success will be whether a particular organizational structure or tool in fact constrains ICANN's authority or in any other way provides an answer to the "problem of discretion." To the extent that ICANN can exercise open-ended policy discretion without accountability, its legitimacy will be in doubt. If a particular organizational structure or tool helps establish either that ICANN's policy discretion is sharply limited or that ICANN is directly accountable to the larger community, then challenges to its legitimacy will be minimized.

\section{LEGITIMIZING ICANN}

\section{A. The Techniques of Administrative Law}

ICANN has structured its policymaking process so that, in important ways, it looks like a typical U.S. federal administrative agency. To begin with, ICANN has loosely followed the techniques of section 553 notice and comment ${ }^{189}$ in undertaking general prospective policymaking. ${ }^{190}$ It has made proposed policy documents available for public comment; ${ }^{191}$ it has held itself open to receive those comments

\footnotetext{
187. See infra Part IV.B.

188. See infra Part IV.C.

189. See 5 U.S.C. $\$ 553$ (1994)

190. Art. III, § 3(b) of ICANN's bylaws provides:
}

With respect to any policies that are being considered by the board for adoption that substantially affect the operation of the Internet or third parties, including the imposition of any fees or charges, the board will:

(i) provide public notice on the Web Site explaining what policies are being considered for adoption and why;

(ii) provide a reasonable opportunity for parties to comment on the adoption of the proposed policies, to see the comments of others, and to reply to those comments; and

(iii) hold a public forum at which the proposed policy would be discussed.

ICANN Amended Bylaws, at http://www.icann.org/general/bylaws.htm (July 16, 2000) (on file with the Duke Law Journal) [hereinafter ICANN Bylaws].

191. See, e.g., Draft Uniform Name Dispute Resolution Policy, at http://www.icann.org/udrp/ udrp-policy-29sept99.htm (Sept. 29, 1999) (on file with the Duke Law Journal). 
for a specified time period ${ }^{192}$ it has allowed commentators to see, and reply to, the public comments filed by others: ${ }^{193}$ and it has sometimes, though by no means always, referred to those comments in documents accompanying the resulting policy announcements. ${ }^{194}$ To be sure, its implementation of this procedure has been flawed. ICANN has been haphazard about comment periods, which have varied in length and have at some times been better suited to the actual eliciting of comments than others. ${ }^{195}$ Moreover, the process of circulating draft documents for comment is hardly unique to the U.S. administrative agency. It is well known to such nonlegal bodies as the Internet Engineering Task Force, the loose body of Internet engineers that historically has played a leading role in developing Internet technology. Still, it's a start; let's keep going.

ICANN has developed a formal procedure for reconsideration of its rulings that may be invoked by "[a]ny person affected." ${ }^{196}$ A request for reconsideration must be filed within thirty days of notice of the contested action and must include information detailing the specific action for which reconsideration is sought and its date, the manner in which the requesting party will be affected by the action, the specific relief requested (reversal, cancellation, or modification), and

192. See, e.g., id. (announcing a two-week comment period).

193. See, e.g., Mail Index, at http://www.icann.org/comments-mail/comment-udrp/current/ maillist.html (last visited Sept. 18, 2000) (providing an archive of public comments submitted in response to the document cited supra note 191) (on file with the Duke Law Journal). On the other hand, ICANN has no rules requiring all comments to be docketed publicly.

194. See, e.g., Second Staff Report on Implementation Documents for the Uniform Dispute Resolution Policy, at http://www.icann.org/udrp/udrp-second-staff-report-24oct99.htm (Oct. 24, 1999) (responding to the comments cited supra note 191) (on file with the Duke Law Journal).

195. One extreme example: ICANN's Elections Committee generated a set of recommendations regarding the conduct of the at-large elections on July 6, 2000, to guide the board at its July 16 meeting. ICANN staff duly posted them for comment, with a July 8 comment deadline. (To be sure, there had been an open comment period since June 23 on a different set of Elections Committee recommendations. If a concerned observer managed to notice, and comment on, the new recommendations in the two-day window supplied, though, it was pure happenstance.)

In response to a suggestion that ICANN needed to adopt formal procedural rules and should consider rules based on the APA, ICANN's CEO answered that APA rules "which are based on a notice-and-comment model of regulatory decisionmaking, do not offer the environment of community participation in deliberative discussions that characterize most aspects of the ICANN process." Letter from Mike Roberts, President and CEO, ICANN, to U.S. Small Business Administration's Office of Advocacy (May 15, 2000), http://www.icann.org/ correspondence/sba-15may00.htm (on file with the Duke Law Journal).

196. ICANN Bylaws, supra note 190, art. III, § 4(a); ICANN Reconsideration Policy, at http://www.icann.org/reconsideration.html (Mar. 26, 1999) (on file with the Duke Law Journal). 
the grounds for that requested relief. ${ }^{197}$ The requesting party may ask for a temporary stay of the action. ${ }^{198}$ If it does so, the party must identify the harms that will result in the absence of a stay. ${ }^{199}$ Upon receipt of those documents, a committee of the board will determine whether an interim stay is appropriate, conduct factual investigation as needed, and make a recommendation to the board on the merits of the request. ${ }^{200} \mathrm{~A}$ request for reconsideration may be dismissed where the affected party "had an opportunity, but was unwilling, to participate in the public comment period relating to the contested action." ${ }^{201}$

ICANN's implementation of this procedure has been flawed but may be improving. The first reconsideration request remained pending for nearly eleven months before the reconsideration committee made a recommendation; ${ }^{202}$ the next three were pending for more than four months. ${ }^{203}$ This fell rather short of ICANN's stated policy that the committee "will endeavor to complete its work and submit its recommendation ... within 30 days. ${ }^{" 204}$ On the other hand, more recent requests have been handled more expeditiously. ${ }^{205}$

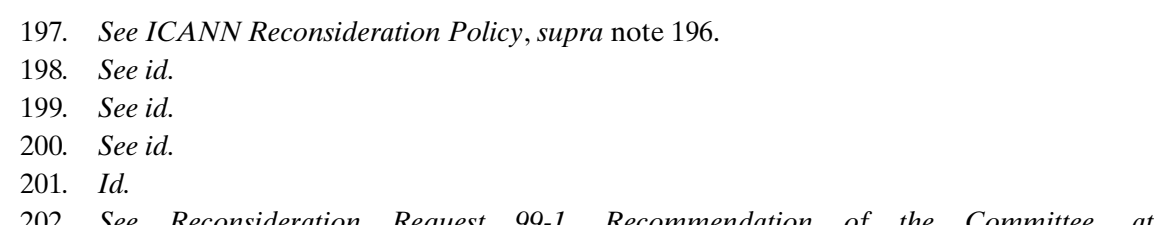

202. See Reconsideration Request 99-1, Recommendation of the Committee, at $\mathrm{http} / / /$ www.icann.org/reconsideration/rc99-1.htm (May 22, 2000) (showing that although the request was filed on June 25, 1999, the reconsideration committee did not issue its recommendation until May 22, 2000) (on file with the Duke Law Journal).

203. See Reconsideration Request 99-2, Recommendation of the Committee, at http://www.icann.org/reconsideration/rc99-2.htm (Jan. 10, 2000) (showing that although the request was filed on August 2, 1999, the reconsideration committee did not issue its recommendation until January 10, 2000) (on file with the Duke Law Journal); Reconsideration Request 99-3, Recommendation of the Committee, at http://www.icann.org/reconsideration/rc99-3.htm (Jan. 27, 2000) (showing that although the request was filed on September 4, 1999, the reconsideration committee did not issue its recommendation until January 27, 2000) (on file with the Duke Law Journal); Reconsideration Request 99-4, Recommendation of the Committee, at $\mathrm{http} / / /$ www.icann.org/ reconsideration/rc99-4.htm (May 2, 2000) (showing that although the request was filed on November 17, 1999, the committee did not issue its recommendation until May 2, 2000) (on file with the Duke Law Journal).

204. ICANN Reconsideration Policy, supra note 196.

205. Of the five most recent reconsideration requests, three were handled within the thirtyday window, one remains shrouded in secrecy, and one is still pending after six months (as of this writing). See Reconsideration Request 00-1, Recommendation of the Committee, at http://www.icann.org/reconsideration/rc00-1.htm (Jan. 27, 2000) (showing that the request was filed January 6, 2000, and the committee recommendation was issued on January 27, 2000) (on file with the Duke Law Journal); Reconsideration Request 00-2, Recommendation of the Com- 
What is most striking about this procedure is its familiarity to students of U.S. administrative law. It incorporates requirements of standing, timeliness, and exhaustion; its application draws on concepts of interim relief and pleading with which the administrative lawyer is well-versed. Of the seven reconsideration committee recommendations made public to date, ${ }^{206}$ three include discussion of procedural issues. Request 99-2 was denied on the ground that it was untimely and did not include required information. ${ }^{207}$ Request 99-3 was denied on the ground that the ICANN board had made no relevant decision, and, thus, there was nothing to reconsider. ${ }^{208}$ In Request 994 , the reconsideration committee undertook an extensive examination of whether the requester had standing and concluded that he did not, before nonetheless proceeding to the merits. ${ }^{209}$ We see here ICANN invoking techniques of process and procedural regularity.

Consider next ICANN's independent review policy. ICANN's initial proposed bylaws provided simply that the board might establish an independent review process "in its sole discretion." ${ }^{210}$ At the insistence of the U.S. government, ICANN's proponents amended the bylaws to require that the board subject itself to outside review. ${ }^{211}$

mittee, at http://www.icann.org/reconsideration (last visited Aug. 18, 2000) (on file with the Duke Law Journal); Request for Reconsideration, Request 00-3, at http://www.icann.org/

reconsideration/wilson-request-10mar00.htm (Mar. 10, 2000) (showing a request that was filed March 10, 2000, and is apparently still pending) (on file with the Duke Law Journal); Reconsideration Request 00-4, Recommendation of the Committee, at http://www.icann.org/

reconsideration/rc00-4.htm (May 22, 2000) (showing that the request was filed on May 6, 2000, and the committee issued its recommendation on May 22, 2000); Reconsideration Request 00-5, Recommendation of the Committee, at http://www.icann.org/reconsideration/rc00-5.htm (May 22,2000 ) (showing a request filed on May 11, 2000, with a committee recommendation on May 22, 2000) (on file with the Duke Law Journal).

206. See supra notes 190, 192 and accompanying text.

207. See Reconsideration Request 99-2, supra note 203.

208. See Reconsideration Request 99-3, supra note 203.

209. See Reconsideration Request 99-4, supra note 203.

210. See Rony, supra note 121 (comparing differing proposals for Art. III, $\S 4$ of the ICANN bylaws).

211. The content of the negotiations between ICANN and U.S. government officials has not been made public. The sequence of events, however, was this: On October 2, 1998, ICANN submitted its initial proposed bylaws, and on November 6, it submitted a new version, revised to reflect concerns expressed by NTIA Associate Administrator Becky Burr in an October 20 letter. Neither version included the independent review requirement. See Rony, supra note 121. On November 18, Ira Magaziner, then the President's senior Internet advisor, was quoted as saying that the new version was still unsatisfactory from the perspective of openness and accountability. See McCullagh, supra note 121. On November 19, Magaziner met with the ICANN board and its counsel. See id. Four days later, ICANN adopted a new set of bylaw changes, including (among other things) the independent review requirement. See Rony, supra note 121 
ICANN adopted its independent review policy after an elaborate and lengthy inquiry, including recommendations from an independent review advisory committee. ${ }^{212}$

Independent review, under this policy, looks a lot like judicial review of agency action. Three-member panels, selected randomly from a nine-member, blue-ribbon pool, examine the contested actions. ${ }^{213}$ The panelists are current or former judges, or lawyers "who would qualify for judicial appointment" with experience conducting arbitration or similar dispute resolution proceedings. ${ }^{214}$ They may not hold an official position within the ICANN structure. ${ }^{215}$

Requests for review can take two forms. First, a request for review can be made on the ground that the board has acted, or failed to act, in a manner contrary to ICANN's articles of incorporation or bylaws. ${ }^{216}$ The requester must have been "materially affected by the contested action or failure to act" and must have first exhausted ICANN's internal reconsideration process. ${ }^{217}$ Should the panel find that the board's action was inconsistent with its articles of incorporation or bylaws, it can require the board to act on that finding within thirty days, and it can recommend that the board stay the contested action in the interim. ${ }^{218}$

Second, ICANN's contracts with NSI (acting as the registry for .com, .net, and .org) and with the various domain name registrars provide that NSI and the registrars need not comply with certain

(showing both the language originally proposed for Art. III, $\S 4$ of the ICANN bylaws and the language eventually adopted). Two days after that, the U.S. government and ICANN signed the memorandum of understanding in which the U.S. government recognized ICANN as the nonprofit entity described in the White Paper. See Memorandum of Understanding, supra note 121.

212. See Internet Corporation for Assigned Names and Numbers Minutes of Meeting, at http://www.icann.org/minutes/minutes-10mar00.htm\#IndependentReviewPolicy (Mar. 10, 2000) (on file with the Duke Law Journal).

213. See ICANN Independent Review Policy, § 3, at http://www.icann.org/indreview/ policy.htm (Mar. 10, 2000) (on file with the Duke Law Journal). The Independent Review Policy sets out an elaborate procedure for the selection of the nine-member Independent Review Panel. Each of ICANN's supporting organizations is to name two members of a six-person nominating committee; the nominating committee sends the names of proposed members of the Independent Review Panel to the ICANN board; the board must approve the Independent Review Panel, as a slate, by a two-thirds vote. See id. $\S \S 4-5$. So far, the nominating committee has not yet been constituted.

214. Id. § 5.12.2.

215. See id. $\$ 5.12 .3$.

216. See id. $\$ 6.1$.

217. Id. $\S \S 6.2,6.3$.

218. See id. $\$ 3.4$. 
ICANN policies unless ICANN's adoption of the policies was supported by "consensus" as defined in the contracts. ${ }^{219}$ The independent review policy provides that a beneficiary of that contractual provision may submit a request for independent review to determine whether an ICANN policy covered by the provision, with which the requester would otherwise have to comply, is, in fact, supported by consensus. ${ }^{220}$ The request must be timely. ${ }^{221}$ The panel bases its decision on the written record supporting the proposal's adoption, looking to the extent of agreement and disagreement among affected groups, the outreach process used to achieve adequate representation of those group's views, and the nature and intensity of reasoned support and opposition to the policy. ${ }^{222} \mathrm{~A}$ decision that the challenged policy is not supported by consensus is self-executing in the sense that it releases NSI and the registrars, by the terms of their contracts, from compliance with the contested policy. ${ }^{223}$

Recall that earlier in this Article I suggested that under the traditional model, federal agencies justify their policymaking discretion with reference to two sets of constraints. First, they must stay within the bounds of their statutory delegations. ${ }^{224}$ Second, their discretion is constrained by requirements of fair process and bureaucratic rationality: the process of notice and comment, together with careful consideration of the comments received, helps ensure that the agency's policy choices are rationally justified. ${ }^{225}$ Judicial review is available to enforce each of those limits.

219. See ICANN-NSI Registry Agreement, $\S \S 1,3 \mathrm{~A}$, at http://www.icann.org/nsi/nsi-registryagreement-04nov99.htm (Nov. 4, 1999) (on file with the Duke Law Journal); Registrar Accreditation Agreement, §§ I.B, I.E, II.D.1.b, supra note 148.

220. See ICANN Independent Review Policy, supra note 213, §§ 7.1, 7.2.

221. See id. \$7.2.

222. See id. $\$ 7.3$.

223. The contracts also provide that NSI and the registrars need not comply with any policy that "unreasonably restrain[s] competition," or that does not relate to

(1) issues for which uniform or coordinated resolution is reasonably necessary to facilitate interoperability, technical reliability, and/or stable operation of the Internet or domain-name system; (2) registry [or registrar] policies reasonably necessary to implement Consensus Policies relating to the registrars [or Registry], or (3) resolution of disputes regarding the registration of domain names (as opposed to the use of such domain names) ....

ICANN-NSI Registry Agreement, §3(A)(ii), supra note 219; Registrar Accreditation Agreement, $\S$ II.D.1.b, supra note 148. Neither the Independent Review Panel nor any other body within the ICANN structure, though, has jurisdiction to determine whether those conditions are satisfied.

224. See supra note 172 and accompanying text.

225. See supra notes 173-75 and accompanying text.

226. See supra notes 172,176 and accompanying text. 
Can ICANN look to this model to legitimate its own exercise of policymaking authority? If we analogize the independent review process to judicial review, then it is easy to think of ICANN as constrained in much the same way as is a federal administrative agencyby rationality and process norms. The first form of independent review-review for consistency with ICANN's articles of incorporation and bylaws-seems analogous to a court's review of agency action for consistency with the agency's enabling statute. ${ }^{227}$ Just as a court seeks to ensure that an agency does not stray outside the bounds of its statutorily delegated authority, the independent review panel seems to be ensuring that ICANN stays within the bounds of its own delegated authority, as defined by the articles and bylaws.

As one examines the analogy more closely, though, it begins to break down. For one thing, ICANN's articles and bylaws do not contain any significant substantive constraints. ${ }^{228}$ As a result, it is nearly impossible for an ICANN policy to be found substantively in conflict with those documents. The analogy to judicial review of agency action fails: were a court reviewing a U.S. federal agency's action in the context of a similarly worded enabling statute, it would have to find the challenged action immune from review because "committed to agency discretion by law." ${ }^{229}$ Nor should this be surprising. The articles and bylaws were not imposed on ICANN by an outside sovereign seeking to constrain it or to bind its powers. Rather, they were drafted initially by ICANN's lawyers and later by its staff. ${ }^{230}$ Those ac-

227. See Chevron U.S.A., Inc. v. Natural Resources Defense Council, Inc., 467 U.S. 837, 844 (1984) (setting out the standard for court review of an agency's construction of its governing statute).

228. The only substantive constraints contained in either document are (1) a ban on ICANN's acting as a registry, registrar or IP number registry in competition with private parties; and (2) an injunction that ICANN may not apply its policies "inequitably or single out any particular party for disparate treatment unless justified by substantial and reasonable cause." ICANN Bylaws, supra note 190, art. IV, §§ 1(b)-(c).

229. 5 U.S.C. $\$ 701(\mathrm{a})(2)(1994)$.

230. See Letter from Jon Postel, Director, Internet Assigned Numbers Authority, to William Daley, Secretary of Commerce (Oct. 2, 1998) (transmitting ICANN's articles of incorporation and proposed bylaws), National Telecommunications and Information Administration, http://www.ntia.doc.gov/ntiahome/domainname/proposals/icann/icann.html (on file with the Duke Law Journal). ICANN's lawyers, to be sure, did not have an entirely free hand in preparing the initial documents. After a lengthy process in which IANA developed several drafts and much of the Internet community sought to achieve consensus on the structure of the new corporation through a process called the International Forum on the White Paper, ICANN's lawyers negotiated a version of the articles and bylaws with NSI. See Contents of Discussion Release, Internet Assigned Numbers Authority, at http://www.iana.org/description2.html (Sept. 17, 1998) (on file with the Duke Law Journal). The documents ICANN proponents submitted to the De- 


\section{tors sought to maximize ICANN's freedom of action and to minimize any enforceable constraints. ${ }^{231}$ The documents are constraining only to}

partment of Commerce were based on that draft as rewritten by ICANN counsel over the intervening two weeks. NSI's participation, however, did not inject significant concerns for public participation or process transparency into the drafting process; the IANA/NSI draft incorporated "vague lines of accountability, limited, if any, means for individual participation, . . . a high degree of susceptibility to capture by companies and organizations, and ... [no guarantee of] a membership structure." Letter from the Boston Working Group to Ira Magaziner, Senior Advisor to the President for Policy Development (Sept. 28, 1998), National Telecommunications and Information Administration, http://www.ntia.doc.gov/ntiahome/domainname/proposals/bosgrp/ (on file with the Duke Law Journal).

All changes to the ICANN bylaws since the initial version was adopted have been prepared by ICANN lawyers and staff and voted upon by its board, as is standard in the corporate context.

231. The bylaws are long on grants of power and short on limitations. Thus, for example, after giving the supporting organizations primary responsibility for initiating substantive policy and prescribing detailed procedures under which supporting organization review is nominally a prerequisite to substantive board action, the bylaws add: "Nothing in this Section . . . is intended to limit the powers of the Board ... to take actions that the Board finds are necessary or appropriate to further the purposes of the Corporation." ICANN Bylaws, supra note 190, art. VI, § $2(\mathrm{~g})$. In practice, the board has paid little attention to the supporting organizations. See infra notes 332-34 and accompanying text (explaining that the Domain Name Supporting Organization has played little role in domain name policy development); Request for Reconsideration 003, at http://www.icann.org/reconsideration/wilson-request-10mar00.htm (expressing concern that ICANN took action without appropriate consultation with the Address Supporting Organization) (on file with the Duke Law Journal). The Protocol Supporting Organization has taken almost no action to date other than selecting ICANN board members. For further reference, see the minutes of the first eight Protocol Council teleconferences, linked from http://www.pso.icann.org. (on file with the Duke Law Journal).

A good example of self-protective language in the bylaws is the insistence that ICANN at-large members, who vote for certain ICANN directors, are not "members" within the meaning of statutory nonprofit corporations law and, thus, may not claim the rights granted by such law. ICANN Bylaws, supra note 190, art. II, § 1. This is tricky, because the applicable law grants statutory membership rights to "any person who, pursuant to a specific provision of a corporation's articles or bylaws, has the right to vote for the election of a director or directors." CAL. CORP. CODE $§ 5056$ (West 1990). ICANN staff seem satisfied that they have solved this problem by providing in the bylaws only that the at-large directors will be "nominated and selected... according to a selection plan adopted by the Board," and adopting the election plan as a board resolution. See E-mail from Louis Touton, Vice President and General Counsel, ICANN, to Karl Auerbach, Advanced Internet Architecture Group, Cisco Systems (Aug. 21, 2000) (on file with the Duke Law Journal).

One egregious example of the bylaws' adoption of incongruous language from the corporate governance context came in an earlier version of the membership provisions, under which the sole function of the at-large membership was to elect members of an "At-Large Council," who would in turn select directors representing the at-large members. ICANN adopted bylaws providing that members could not permit any other person to exercise their voting rights, except that they could grant proxies to ICANN staff. See ICANN Bylaws, supra note 190 , art. II, $\S 5$. That ICANN amended its bylaws to set up a process under which individual members of the global Internet community would (indirectly) select their own directors, in order to make the process for choosing board members sufficiently broad-based and meaningfully representative, but contemplated that the members could simply give their proxies to 
the extent that the U.S. government applied pressure to make them so. $^{232}$

In addition, ICANN's independent review process is unlike traditional judicial review in that the panel has no authority to engage in rationality review. ${ }^{233}$ The panel has no authority to disapprove an ICANN action on the ground that it is unreasonable, arbitrary, or an abuse of discretion. ${ }^{234}$

Without external review for rationality and statutory faithfulness, the traditional model collapses. In the administrative agency context, it is judicial review that drives the agency's commitment to process and rationality. ${ }^{235}$ The agency is constrained to read and respond to comments precisely because it knows that it is subject to judicial reversal if it does not do so. $^{236}$ The agency formulates its policy determinations with the understanding that a court may demand proof that the agency, at each stage of its reasoning process, considered and reasonably rejected alternative approaches. ${ }^{237}$ Without judicial review, the agency would not have adequate incentives to honor process and rationality values punctiliously. ${ }^{238}$ Yet there is no ICANN institution that performs the function that judicial review performs for administrative agencies.

ICANN staff to install the staff's own choices, betrays an extreme case of being unclear on the concept.

232. For an account of the government pressure that resulted in the adoption of the independent review requirement, see supra note 211.

233. See ICANN Independent Review Policy, supra note $213, \S 2$.

234. A court engaging in APA review has precisely this authority under 5 U.S.C. $§ 706$.

235. See William F. Pedersen, Jr., Formal Records and Informal Rulemaking, 85 YALE L.J. 38, 60 (1975):

It is a great tonic to a program to discover that even if a regulation can be slipped or wrestled through various layers of internal or external review [within the bureaucracy] without significant change, the final and most prestigious reviewing forum of all-a circuit court of appeals-will inquire into the minute details of methodology, data sufficiency and test procedure and will send the regulations back if these are lacking. The effect of such judicial opinions within the agency reaches beyond those who were concerned with the specific regulations reviewed.

236. See id. at 59 .

237. See, e.g., Motor Vehicle Mfrs. Ass'n v. State Farm Mut. Auto. Ins. Co., 463 U.S. 29, 4651 (1983) (finding the NHTSA's recission of passive restraint vehicle safety requirements "arbitrary and capricious" in part because of the NHTSA's failure to consider available airbag technology as an alternative).

238. See Merrick Garland, Deregulation and Judicial Review, 98 HARV. L. REV. 505, 553 (1985) (citing the role of judicial review in ensuring careful attention to administrative process); Cass R. Sunstein, Constitutionalism After the New Deal, 101 HARv. L. REv. 421, 471 (1987) ("The requirement of detailed explanation has been a powerful impediment to arbitrary or improperly motivated agency decisions."). 
I am not arguing here that ICANN should be subject to judicial review. ${ }^{239}$ My point, rather, is that without judicial review, the tech-

239. Michael Froomkin, in his article in this issue, argues precisely that. See Froomkin, supra note 34, at 129-39. For three reasons, though, I am skeptical of judicial review of ICANN decisions. First, the administrative-law process of generalist (often uninformed) courts reviewing specialist agencies works as well as it does because of the process of rule-remand-rule. That is, the reviewing court, upon deciding that an agency action is procedurally flawed or inadequately explained, does not substitute its own judgment; instead, it remands to the agency so that the agency can correct its mistakes. There are drawbacks to this approach. For one thing, it is slow. The process of getting into court takes time, and judicial review is followed by lengthy postremand proceedings. See Stephen Breyer, Judicial Review of Questions of Law and Policy, 38 Admin. L. ReV. 363, 383 (1986); Peter H. Schuck \& E. Donald Elliott, To the Chevron Station: An Empirical Study of Federal Administrative Law, 1990 DUKE L.J. 984, 1050. More importantly, judicial review offers a powerful weapon to champions of the status quo, see Breyer, supra, at 391-93, as industry members use it to block or delay agency initiatives, see Jerry L. Mashaw \& David L. Harfst, Regulation and Legal Culture: The Case of Motor Vehicle Safety, 4 YALE J. ON REG. 257, 294-95 (1987). Although the politically powerless often see judicial review as their way to impose legality on a captured agency, see Cass R. Sunstein, On the Costs and Benefits of Aggressive Judicial Review of Agency Action, 1989 DUKE L.J. 522, 522-23 (1989), judicial review can as easily (or more easily) be used by powerful, moneyed actors with other motivations to reverse or forestall agency action. See Mashaw \& Harfst, supra, at 257.

In the agency context, we are willing to tolerate these drawbacks, and the possibility of agency stasis, as part of the price for legal control of agency decisionmaking. In the ICANN context, however, they pose greater problems. An entity that seeks to operate on "Internet time" is especially ill-served by such delays. A key part of ICANN's mission is to change the name space by adding new TLDs, and ICANN, after a long wait, is finally moving to expand the name space to a limited degree. If it were generally understood that ICANN's decision to allow new gTLDs were subject to review in U.S. courts, I expect that that plan would now be on hold as trademark and other affected interests raised judicial challenges to the thrust and details of ICANN's plan. The power of judicial review to block desirable initiatives such as domain name expansion (and prophylactically to dampen decisionmakers' enthusiasm for such initiatives), and to provide yet another vehicle for industry arguments that that any expansion must be accompanied by stringent trademark protective mechanisms, weighs against its appeal.

Second, if it were widely accepted that U.S. courts could review ICANN decisionmaking, it would follow as a corollary that the U.S. Congress as well could impose its policy choices. Currently, Congress has the raw power to issue policy directives to ICANN, see Testimony of Jon Weinberg to COPA Commission, at http://www.icann.org/correspondence/jon-weinbergCOPA-testimony-08jun00.htm (June 8, 2000) (on file with the Duke Law Journal), but there is a strong sense that it would be inappropriate for it to do so because Congress should not overrule or preclude ICANN decisions in ICANN's area of core expertise. If ICANN decisions were to become the routine subject of APA review, I suspect that that reluctance would fade. It seems to me that this would not be a good thing. The concerns that ICANN critics express regarding the influence of moneyed interests in ICANN are, if anything, amplified in the halls of Congress. For all of ICANN's flaws, I suspect that ICANN with Congress's help could wreak much more mischief, and would be even more beholden to moneyed interests, than ICANN alone.

Finally, because the domain name and IP address space are global, it seems at best anachronistic to institute a legal regime under which the courts of a single country control it. Indeed, it seems a fair prediction that if U.S. courts asserted the power to review ICANN's decisionmaking, then courts in other countries would attempt to do the same thing. The resulting jurisdictional battles would not be pretty, and the substantive law those courts sought to apply 
niques of administrative law do not solve the problem of discretion. Notwithstanding its reliance on process and structures familiar to students of administrative law, ICANN cannot make the claim that the values of the traditional administrative law model-bureaucratic rationality and procedural regularity-will control its discretionary power. ICANN staff can request public comments on proposed actions and can entertain petitions for reconsideration of those actions once made, but there is nothing in the techniques of administrative law, as practiced by ICANN, to guarantee that anybody will take those comments seriously, or that the resulting policy will make sense in light of the objections contained in the comments. Further, there is nothing in the techniques of administrative law, as practiced by ICANN, to confine ICANN within any particular sphere of authority. ${ }^{240}$ Those guarantees must come from elsewhere.

\section{B. The Techniques of Representation}

The fact that administrative law mechanisms do not limit ICANN's processes and authority does not mean that other mechanisms might not do so. Another potential limit on ICANN's autonomy lies in its representational structure. Both ICANN's board of directors and its subsidiary bodies - the supporting organizations-have been self-consciously designed so as to include representatives of a range of Internet "stakeholders." ${ }^{241}$ One might expect ICANN, therefore, to act in a manner responsive to those stakeholders. To the extent that ICANN's structure fairly reflects the Internet community, ICANN's decisions would track the preferences of that community. In that case, we could solve the problem of discretion not by constraining the agency, but by ensuring that its decisions are the product of a democratic process.

Representation, however, is not an easy thing. Let us examine ICANN's structure more carefully. ICANN's board of directors has

might not be appealing. Although the existing legal regime gives a U.S. executive agency-the Department of Commerce-explicit authority over any changes to the root zone and extensive informal influence over ICANN, the U.S. government has assured other countries that it will not be in place for the long term. See White Paper, supra note 26, at 31,744 (indicating that the United States would end its policy oversight of ICANN by September 30, 2000); Amendment 2 to ICANN/DOC Memorandum of Understanding, at http://www.icann.org/general/amend2jpamou-07sep00.htm (Sept. 7, 2000) (extending the Department of Commerce's memorandum of understanding with ICANN for up to another year) (on file with the Duke Law Journal).

240. But see the contractual language quoted supra note 223.

241. See supra notes 97-99, 106-07, infra notes 247-51, 260-61, 292-95 and accompanying text. 
nineteen members. ${ }^{242}$ The first of these is ICANN's CEO, who has an automatic seat on the board. ${ }^{243} \mathrm{Next}$, each of three supporting organizations - the Domain Name Supporting Organization (DNSO), the Address Supporting Organization (ASO), and the Protocol Supporting Organization (PSO) - selects three board members. ${ }^{244}$ The supporting organizations are subsidiary ICANN bodies; according to ICANN's bylaws, each has primary authority for policy development in its area of expertise..$^{245}$ The Domain Name Supporting Organization, thus, has primary responsibility for developing policy relating to domain names; I shall discuss it in more detail below. The responsibilities of the Address Supporting Organization relate to the operation, assignment, and management of IP addresses. ${ }^{246}$ As a practical matter, the three ASO members of the ICANN board represent each of the three Regional Internet Registries, which allocate IP address blocks in the Americas, Europe, and Asia, respectively. ${ }^{247}$

The Protocol Supporting Organization, according to the bylaws, has jurisdiction over "the assignment of parameters for Internet protocols." ${ }^{248}$ In fact, ICANN has no significant policymaking functions relating to protocol parameter assignment. ${ }^{249}$ Rather, the PSO was

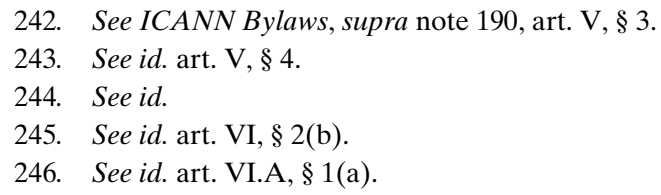

247. The ASO members of the board are selected by the nine-member Address Council, whose members are chosen exclusively by the RIRs. See ICANN Address Supporting Organization Memorandum of Understanding, §§ 2-3, The Address Supporting Organization, at http://www.aso.icann.org/docs/aso-mou.html (last visited Sept. 21, 2000) (on file with the Duke Law Journal). The three board members must come from three different geographic regions. See id. § 3(c). To date, all of them have come from the three regions served by the RIRs. See The Address Supporting Organization: Address Council Representatives on ICANN Board, The Address Supporting Organization, at http://www.aso.icann.org/board (last visited Oct. 11, 2000) (on file with the Duke Law Journal).

248. ICANN Bylaws, supra note 190, art. VI.C, § 1(a).

249. The Protocol Supporting Organization Memorandum of Understanding, signed by ICANN and by the standards development organizations that formed the PSO, urges that "policies for parameter assignments for particular protocols are the responsibility of the [standards development organization] that developed the protocol," and that the relevant ICANN policy development function is simply to be available, as needed, to develop policies and procedures to resolve conflicts between standards development organizations, with those organizations' consent. Protocol Supporting Organization Memorandum of Understanding, § 4(b), The Protocol Supporting Organization, at http://www.icann.org/pso/pso-mou.htm (July 14, 1999) (on file with the Duke Law Journal). ICANN has expressly confirmed that position. See E-mail from Esther Dyson, Interim Chairman, ICANN, to Scott Bradner et al., ISOC VP for Standards, Internet Engineering Task Force (Feb. 25, 1999), http://www.icann.org/correspondence/bradner-dyson- 
conceived of by U.S. government policymakers as a way of ensuring the Internet engineering community a voice in ICANN decisionmaking. ${ }^{250}$ Ironically, as the PSO was finally constituted, its governing Protocol Council ended up including representatives not only of the Internet Engineering Task Force and the World Wide Web Consortium, both bastions of Internet open-networking values, but also of the International Telecommunications Union and the European Telecommunications Standards Institute, often seen as hostile to those values. ${ }^{251}$ The current PSO board members hail from the Internet Engineering Task Force, the World Wide Web Consortium, and the European Telecommunications Standards Institute, respectively. $^{252}$

ICANN's bylaws allocate the remaining nine seats on the board to "at-large" members ${ }^{253}$ and characterize ICANN's nine initial board members as filling those slots (notwithstanding that the Internet community at large had no role in their selection). ${ }^{254}$ More recently, ICANN has moved to implement a plan under which five of the initial board members will be replaced by directors elected by individual ICANN members in each of five geographical regions; I shall describe that plan in more detail below. ${ }^{255}$

First, though, it's useful to examine the Domain Name Supporting Organization. As noted above, ICANN's bylaws give the supporting organizations primary authority for policy development in their areas of expertise. ${ }^{256}$ The recitations in the bylaws suggest that as a general matter, ICANN can take no substantive action relating to domain names unless it has received a recommendation to that effect

25feb99.htm\#Dyson (on file with the Duke Law Journal). There is no particular reason to think that any such conflict will ever arise.

250. The author participated in this aspect of the U.S. government's policy development process, as a legal-scholar-in-residence at the Federal Communications Commission and a member of the interagency working group addressing DNS issues, prior to the release of the Green Paper.

251. On the ITU, see Comments of the United States ITU Association on the SecretaryGeneral's IP Networks Report, World Internetworking Alliance, at http://www.wia.org/ITU/ usitu_assoc_comments.htm (Dec. 3, 1999) (on file with the Duke Law Journal). On ETSI, see Letter from John C. Klensin, Interim Director, Internet Architecture Board, to ICANN Board (Aug. 13, 1999), http://www.icann.org/comments-mail/comment-aso/msg00013.html (on file with the Duke Law Journal).

252. See About ICANN, supra note 185.

253. See ICANN Bylaws, supra note 190, art. V, § 4(iv).

254. See id.

255. See infra notes 285-308.

256. ICANN Bylaws, supra note 190, art. VI, § 2(b). 
from the DNSO. ${ }^{257}$ As the only specialist body within ICANN concerned with domain names, and the only supporting organization that has essayed actual policymaking, the DNSO is worthy of careful study.

The DNSO is divided into two bodies: a policymaking organ known as the Names Council and a vestigial appendix known as the General Assembly. ${ }^{258}$ The General Assembly is open to all individuals with an interest in domain name policy who choose to join it; it labors, however, under the handicap of having no function and no authority. ${ }^{259}$ Notwithstanding the efforts of an able and dedicated chair, Roberto Gaetano, it is essentially moribund.

The Names Council includes a representative from NSI and three representatives from each of six additional "constituencies": (1) commercial and business entities; (2) trademark interests; (3) firms registering names in .com, .net, and .org; (4) Internet service providers and connectivity providers; (5) country code top-level domain registries; and (6) noncommercial organizations holding domain names. ${ }^{260}$ Each of these constituencies comprises a set of firms or noncommercial organizations that, at ICANN's direction, "selforganized" into a body that could take a seat at the Names Council table. ${ }^{261}$

257. The bylaws provide the following exceptions: (1) if the board has been unsuccessful, after reasonable effort, at soliciting a DNSO recommendation that it can approve; (2) if the board has been unsuccessful at mediating a dispute over the policy between the DNSO and one or both of the other supporting organizations; or (3) if bypassing the DNSO is "necessary or appropriate to further [ICANN's] purposes." Id. §§ 2(f)-(g).

258. See id. art. VI.B, § 1(b).

259. The bylaws recite that the General Assembly "shall be an open forum for participation in the work of the DNSO." Id. art. VI.B, § 4(a). Individual members of the General Assembly may participate in "research and drafting committees and working groups" chartered by the Names Council. Id. The only function given by the bylaws to the General Assembly as a body, though, is to "nominate, pursuant to procedures adopted by the NC and approved by the Board," the DNSO members of the ICANN board. Id. art. VI-B, \& 4(d). Under the Names Council's procedures, a candidate shall be deemed nominated if he is endorsed by at least ten members of the General Assembly. See DNSO Election of ICANN Board Member in 2000, Domain Name Supporting Organization, at http://www.dnso.org/elections/2000.DNSO-ICANNnomination-proc.html (last visited Sept. 19, 2000) (on file with the Duke Law Journal). Experience has shown this to be an inconsequential hurdle.

260. See ICANN Bylaws, supra note 190, art. VI.B, §§ 3(b)-(c). ICANN's bylaws describe seven constituencies, including the "gTLD registries" constituency, and recite that each constituency is entitled to three Names Council members. See id. NSI, however, is the sole member of the gTLD registries constituency, and "no Constituency may have more representatives... than there are members of the Constituency." Id. art. VI.B, § 3(c).

261. In March 1999, ICANN resolved that "[t]he DNSO structure should include selforganized constituency groups of organizations and/or individuals with interest and expertise in 
The constituency system for populating the Names Council has been the target of extensive criticism. In the words of one wellrespected observer, the constituency structure is "a fundamental reason for the DNSO's problems," a "failure" that "should be abandoned." "262 The constituency structure has generated underrepresentation, because many interested parties cannot find a home in any of the approved constituencies; overrepresentation, because other parties can participate in multiple constituencies; and misrepresentation, because the selection of constituency representatives obscures significant differences of opinion within the constituencies. ${ }^{263}$ Certainly, the list of constituencies ICANN selected seems skewed. There is a considerable overlap, after all, between commercial entities and trademark interests; on the other hand, individual domain name holders and ordinary Internet end-users, whom one would think have an interest in domain name policy development, are not represented on the Names Council at all. The more basic problem, though, lies not in the choice of particular constituencies, but in the incoherence of the underlying structure. Even if nobody were excluded, there would be no reason to think that we could reflect the views of the domain name community by identifying a set of activities necessary to, or enabled by, the domain name system or the Internet in general, collecting in-

DNSO matters," and that the initial DNSO constituency groups should be the seven industry groups (including NSI) set out above. Domain Name Supporting Organization Formation Concepts, at http://www.icann.org/dnso-formation.html (Mar. 4, 1999) (on file with the Duke Law Journal). The board directed each of those constituencies to organize itself and submit a formal proposal for recognition. At ICANN's next meeting, in May 1999, the board "provisionally recognized" six of the seven, with the direction that the recognized constituencies should work with ICANN staff to amend their proposals to address such issues as criteria for participation in the constituency and geographic diversity. The board did not recognize the proposed noncommercial domain name holders constituency because the various individuals and entities seeking to participate in the organization of that constituency were still at loggerheads over key issues. The board would provisionally approve that constituency, limited to noncommercial organizations holding domain names, three months later. Although a variety of commentators had supported a constituency for individual domain name holders, the board in May noted its earlier statement that "no applications for additional constituencies would be considered until the original constituencies it had established in [March] were constituted." ICANN Minutes, at http://www.icann.org/minutes/minutes-27may99.htm (May 27, 1999) (on file with the Duke Law Journal).

262. Posting of Harald Alvestrand, Alternate Chair of the DNSO General Assembly, to ga@dnso.org (Aug. 30, 2000), Domain Name Supporting Organization, http://www.dnso.org/ clubpublic/ga/Arc05/msg00398.html (on file with the Duke Law Journal).

263. See id. 
dustry actors performing each of the activities on the list, and then giving equal votes to each group. ${ }^{264}$

The list of constituencies included in the Names Council reflects the political strength of the various actors at the time the institution was established. ${ }^{265}$ That constituency formation process neatly illustrated the lessons of Mancur Olson's The Logic of Collective Ac$t_{i o n}{ }^{266}$ - that is, it advantaged groups for whom the costs and benefits of domain name policies were concentrated at the expense of those for whom those costs and benefits were widely distributed. Over the past eighteen months, advocates of an individual domain name owners' constituency have sought to press their case to the board. They

264. The Names Council structure may make more sense if we think of the Names Council not as a representative body, but rather as consensus-based. If the idea is that any industry actor represented on the Names Council should have the power to object to a proposal and thus block consensus, then relative voting strength becomes unimportant; the only question is whether every important actor in fact has a Names Council representative that can exercise its veto. On that approach, see infra Part IV.C.

265. ICANN's decision in Singapore followed months of negotiation and jockeying among various actors proposing various structures for the yet-to-be-established DNSO. One group of players held a series of meetings around the world to negotiate a DNSO structure. According to the group's "Monterrey draft," the Names Council constituencies would be registries, registrars, infrastructure and connectivity providers, "businesses and other organizations," "[o]rganizations primarily concerned with the interests of trademark owners," and an "[a]t [1]arge" constituency for otherwise unrepresented entities. Monterrey Draft, § I.B, in Comparison of Draft Applications to Become the Domain Name Supporting Organization, at http://www.domainhandbook.com/comp-dnso-bak.html (Dec. 16, 1998) (on file with the Duke Law Journal). The later "BMW" (Barcelona-Monterrey-Washington) proposal by the same group eliminated the at-large constituency but added a new constituency for "[n]on-commercial groups, bodies and associations" and clarified that the business constituency was intended for entities "engaged in commerce or business." Application to Become the Domain Name Support Organization, § I.B, World Information Technology and Services Alliance, at http://www.witsa.org/press/domainapp.htm (last visited Sept. 19, 2000) (on file with the Duke Law Journal). The BMW proposal was countered by a "Paris draft" spearheaded by NSI, which contemplated no official list of constituencies. Rather, in addition to the registry constituency, any group with the allegiance of five percent of the General Assembly members, not "based on geographic location, religious affiliation, governmental affiliation, or membership in any particular corporation or organization," could claim constituency status. Paris Draft Proposal, § 3.2, at http://www.domainhandbook.com/comp-dnso.html (Feb. 4, 1999) (on file with the Duke Law Journal). ICANN in Singapore essentially adopted the BMW list but increased NSI's influence by breaking the "registry" group into gTLD and ccTLD constituencies. See Domain Name Supporting Organization Formation Concepts, supra note 261. ICANN later cut back NSI's sway by adopting the bylaws language under which NSI's Names Council representatives were reduced to one. See ICANN Bylaws, supra note 190, art. VI.B, § 2(g); supra note 247.

266. MAncur Olson, The Logic Of Collective ACtion 128 (1965) (explaining that smaller, organized groups will triumph over larger, unorganized groups in the political arena); see also JAMES Q. WILSON, THE POLITICS OF REgUlATION 366-70 (1980) (describing the typical situations in which constituencies will form). 
have failed so $\operatorname{far}^{267}$ for two reasons. First, absent enthusiasm for the proposal from any major industry player, the board and the Names Council have felt no special urgency to move forward. Indeed, it runs counter to the interests of current Names Council members to dilute their influence by agreeing to the formation of additional constituencies. $^{268}$ Second, proponents have not succeeded in organizing individual domain name holders into any broad-based and representative group onto which the mantle of "constituency" could fall. Absent such a group-and individual domain name holders, each of whom has only diffuse interests in Internet governance, have little incentive to join or organize such a group - the board is reluctant to accredit a constituency.

The constituency structure has also handicapped the Names Council by encouraging council members to think of themselves as representatives of their particular industries. ${ }^{269}$ This has made them more likely to hold on to their constituents' official bargaining posi-

267. As noted supra note 261, the board declined to consider the formation of an individual domain name holders' constituency at its Berlin meeting in May 1999. The August 1999 meeting of the DNSO General Assembly reached consensus that the Names Council should create a working group to examine such a constituency. See Scribe's Notes-ICANN DNSO General Assembly, Berkman Center for Internet and Society, at http://cyber.law.harvard.edu/icann/ santiago/archive/dnso-082499.html (Aug. 24, 1999) (on file with the Duke Law Journal). No working group was formed. In its July 2000 meeting, the General Assembly passed a resolution reaffirming its support in principle for the constituency. See Scribe's Notes-ICANN DNSO General Assembly, Berkman Center for Internet and Society, at http://cyber.law.harvard.edu/ icann/yokohama/archive/scribe-ga-071400.html (July 14, 2000) (on file with the Duke Law Jour$n a l)$. At the board's public forum the following day, Names Council Chair Ken Stubbs indicated that the Names Council would create a working group to address the matter. See Scribe's Notes-ICANN Public Forum, Berkman Center for Internet and Society, at http://cyber.law.harvard.edu/icann/yokohama/archive/scribe-icann-071500.html (July 15, 2000) (on file with the Duke Law Journal). No such working group has been created, but the Names Council has set up a committee to coordinate an overall review of the DNSO structure. See DNSO Names Council Teleconference on 21 September 2000-Minutes, Domain Name Supporting Organization, at http://www.dnso.org/dnso/notes/20000921.Nctelecon-minutes.html (Sept. 21, 2000) (confirming that the initial review report will be produced by a Names Council Task Force).

268. Cf. ELY, supra note 153, at 103 (1980) ("Malfunction occurs when ... the ins are choking off the channels of political change to ensure that they will stay in and the outs will stay out.").

269. See E-mail from Harald Alvestrand, Alternate Chair of the DNSO General Assembly, to the ga@dnso.org mailing list (Aug. 30, 2000), Domain Name Support Organization, http://www.dnso.org/clubpublic/ga/Arc05/msg00398.html (on file with the Duke Law Journal). The constituency structure, Alvestrand urges, has contributed to polarization, as "those who are in the DNSO to represent a constituency feel obliged to serve that constituency's interests whether that makes sense in a global context or not." Id. The DNSO's difficulty "in reaching anything like a consensus position on *anything* is rooted in the constituency structure." Id. 
tions and less likely to work together to develop good policy without the blinders imposed by those institutional identities. ${ }^{270}$

It is hard to argue that the Names Council represents the domain name community in any meaningful way. From a policy development standpoint, however, that turns out to matter less than it might. Notwithstanding the ICANN bylaws, the Names Council has played little role in domain name policy development. In one prominent instance, the renegotiation of NSI's continued management of the .com, .net, and .org databases, ${ }^{271}$ the Names Council was not even consulted. ${ }^{272}$ In another, the development of the Uniform Dispute Resolution Procedure, a proposal generated by a working group and rubber-stamped by the Names Council was set aside by the board in favor of a proposal drafted by an industry group, ${ }^{273}$ with the understanding that the new proposal would be modified further by ICANN's general counsel in consultation with outsiders chosen by ICANN staff. ${ }^{274}$ The Names Council was unable to generate any coherent recommendations regarding protections for the holders of so-called "famous" trademarks against the registration of second-level domains similar or identical to those marks. ${ }^{275}$ When it came to the addition of new generic top-level domains, the Names Council produced a statement of such stunning

270. See id.

271. See Approved Agreements, supra note 140.

272. At the November 1999 Names Council meeting, several Names Council members expressed frustration regarding that process, urging that the agreements made policy that was "the core business of the DNSO." Scribe's Notes-DNSO Names Council, § V.A, Berkman Center for Internet and Society, at http://cyber.law.harvard.edu/icann/la/archive/scribe-nc-110299.html (Nov. 2, 1999) (on file with the Duke Law Journal). At the ICANN board meeting the following day, a Names Council representative expressed "concern" on behalf of the council that the new contracts were not the product of ICANN's professed bottom-up process. See Scribe's NotesICANN Public Meeting, § II.B.4, Berkman Center for Internet and Society, at http://cyber.law.harvard.edu/icann/la/archive/scribe-110399.html (Nov. 3, 1999) (on file with the Duke Law Journal).

273. See Michael Froomkin, Consensus Has Not Been Established on Dispute Policy, at http://www.icannwatch.org/archives/essays/940255991.shtml (Oct. 13, 1999) (on file with the Duke Law Journal); ICANN Minutes, at http://www.icann.org/minutes/minutes26aug99.htm\#UDRP (Aug. 26, 1999) (on file with the Duke Law Journal).

274. See Froomkin, supra note 273; Staff Report on Implementation Documents for the Uniform Dispute Resolution Policy, at http://www.icann.org/udrp/staff-report-29sept99.htm (Sept. 29, 1999) (on file with the Duke Law Journal).

275. The Names Council did recommend that "there should be varying degrees of protection for intellectual property during the startup phase of new top-level domains," but left unstated the nature and strength of that protection and how it should be achieved. DNSO Names Council Resolution on Famous Trade-Marks and the Operation of the Domain Name System, Domain Name Supporting Organization, at http://www.dnso.org/dnso/notes/20000519.NCftmresolution.html (May 19, 2000) (on file with the Duke Law Journal). 
generality that ICANN staff were hardly constrained in crafting their own proposal to the board. ${ }^{276}$ Indeed, the key policy decisions relating to adding new gTLDs, as well as a proposed country code top-level domain for the European Union, are currently being handled by ICANN staff, under the supervision of the board, with no participation by the Names Council. ${ }^{27}$

The Names Council has so far proved itself incapable of developing policy. Its members are disinclined to spend extensive time outside of meetings using e-mail to thrash out details. The Council, which has no staff, has taken the approach that it should primarily rely on policy work done by the working groups it charters and should ratify the consensus, where appropriate, that those groups bring forward. Yet where a working group is unable to reach a conclusion, or where the Names Council is unwilling to endorse a working-group recommendation, as in the two major policy issues to come before it most recently, the council has been largely mute. ${ }^{278}$ Its members wrangle for several hours at their meetings, adopt a policy statement at a level of generality high enough to satisfy nearly all of them, and leave the remaining issues to ICANN staff in the guise of "implementation." 279

276. See DNSO Names Council Statement on New gTLDs, Domain Name Supporting Organization, at http://www.dnso.org/dnso/notes/20000419.NCgtlds-statement.html (Apr. 19, 2000) (on file with the Duke Law Journal).

277. After receiving the Names Council statement, ICANN staff prepared a discussion document on the introduction of new TLDs. See ICANN Yokohama Meeting Topic: Introduction of New Top-Level Domains, at http://www.icann.org/yokohama/new-tld-topic.htm (June 13, 2000) (on file with the Duke Law Journal). The document requested public comment on 74 policy and technical questions that would have to be answered in connection with the rollout. Those questions, in turn, were just a subset of those that staff might have chosen to ask. For a survey of the key policy issues raised by the deployment of new top-level domains, see Interim Report of Working Group C of the Domain Name Supporting Organization, Domain Name Supporting Organization, at http://www.dnso.org/dnso/notes/19991023.NCwgc-report.html (Oct. 23, 1999) (on file with the Duke Law Journal). Almost none of these issues were addressed by the Names Council; they were left to be decided, either explicitly or sub silentio, by the ICANN staff and board.

278. See supra notes 262-63 and accompanying text. The two policy issues related to the introduction of new gTLDs and the protection of famous trademarks. In the former case, the Names Council declined to endorse a key consensus point reached by the working group. See DNSO Names Council Teleconference Minutes, Domain Name Supporting Organization, at http://www.dnso.org/dnso/notes/20000418.NCtelecon-minutes.html (Apr. 18, 2000) (on file with the Duke Law Journal). In the latter, the working group was unable to reach rough consensus on any significant point other than that some form of protection would be desirable. See WG-B Final Report, Domain Name Supporting Organization, at http://www.dnso.org/dnso/ notes/20000515.NCwgb-report.html (May 15, 2000) (on file with the Duke Law Journal).

279. This description should be familiar to any observer masochistic enough actually to listen (via webcast, or conference call listen-only line) to a Names Council meeting. A RealAudio 
ICANN staff then address the policy issues in the way they think best. $^{280}$

In sum, the Names Council is not a place where policy is made by individuals who meaningfully represent the domain name community as a whole. The Names Council's structure is not especially representative, and the Council has been able to make little policy. Let's look instead to the representational structure of the ICANN board itself, as it is the board that is ultimately responsible for ICANN's policy choices. ${ }^{281}$ Does that body better reflect the Internet community at large?

ICANN cannot claim to represent the Internet community on the basis of its supporting organization-selected members. To the extent that the Names Council itself lacks representative credentials, there is no reason to think that its selections for the ICANN board ${ }^{282}$ would bolster the board's legitimacy. The directors chosen by the ASO and PSO stand on somewhat better footing. Given ICANN's IP address responsibilities and the dominant role of the Regional Internet Registries (RIR) in the IP allocation process, it seems hardly unreasonable to give the RIRs, through the ASO, a voice on the board; the position of the ASO board members is bolstered by the fact that the current ASO directors are well-respected for their accomplishments and technical expertise. ${ }^{283}$ Similarly, the credibility of the PSO selections is bolstered by the strong technical credentials of the individuals concerned. ${ }^{284}$ The PSO and ASO representatives include worthy and important voices. Yet this structure, without more, excludes

version of a recent meeting can be found at http://cyber.law.harvard.edu/ (last visited Sept. 21, 2000).

280. See supra notes 262-65 and accompanying text.

281. See ICANN Bylaws, supra note 190, art. IV, § 1(a).

282. Currently, the DNSO-selected members of the board are Amadeu Abril i Abril, a Spanish law professor associated with a domain name registrar; Jonathan Cohen, a Canadian intellectual property lawyer; and Alejandro Pisanty, Director of Computing Academic Services at the National Autonomous University of Mexico. See About ICANN, supra note 185. These selections reflect geographical diversity rules imposed by the board, under which the three directors must hail from different geographical regions. The DNSO is alone among the supporting organizations in choosing lawyers, rather than technical people, as two of its three representatives on the board.

283. They are: Rob Blokzijl of the Netherlands, a founding member and Chair of RIPE, the European open forum for IP networking; Ken Fockler, a Canadian networking pioneer and leader; and Pindar Wong of Hong Kong, a leader of the East Asian Internet community. See id.

284. They are: Jean-François Abramatic, the (French) Chair of the World Wide Web Consortium; Vinton Cerf, respected Internet pioneer and founding President of the Internet Society; and Philip Davidson, a British Telecom expert on telecommunications standards. See id. 
many interested in, and affected by, ICANN's policymaking with different perspectives and views. The directors can hardly be said to represent the Internet community at large.

From its inception ICANN committed to addressing this problem by including on its board a set of "at-large" directors drawn from the broader Internet community. ${ }^{285}$ The nature and meaning of the atlarge structure, though, has been hotly contested. Joe Sims, who was hugely influential in ICANN's formation as its outside counsel, ${ }^{286}$ was openly skeptical about the value of allowing individual Internet users to participate in ICANN's management, except as part of the supporting organizations. ${ }^{287}$ ICANN's initial bylaws proposal provided simply that the at-large directors would be "selected pursuant to a process to be established by a majority vote of ... the Initial Board." ${ }^{288}$ The proposal included no commitment that individual members would play a role in the selection (or, indeed, that ICANN would have individual members). ${ }^{289}$ That aspect of the proposal was received coolly by Ira Magaziner and the Department of Commerce; the Department noted its concern that without members, ICANN would not operate in an adequately bottom-up and representative manner, open to input from the broad community of Internet users. ${ }^{290}$ It urged ICANN to amend its plans so as to assure "greater accountability of the board of directors to the Internet community." 291

285. The White Paper, ICANN's foundational document, required that ICANN's board represent not only membership organizations concerned with numbers, names and protocols, but also "the direct interests of Internet users." White Paper, supra note 26.

286. See Byfield, supra note 134. Postel had sent an RFP in April 1998 to 12-15 law firms for pro bono legal services, including drafting ICANN's bylaws. See E-mail from Michael M. Krieger, Partner, Krieger \& Nunziato, LLP, to Professor Jonathan Weinberg, Wayne State University Law School (Sept. 15, 2000) (on file with the Duke Law Journal). Sims's firm was selected. See Byfield, supra note 134.

287. Sims believed that the idea of an individual membership electing board members was unworkable and misguided. See Sims, supra note 183. Indeed, it was "fundamentally wrongheaded," because it was "clearly not consistent with the principal objective of ICANN: create a vehicle for consensus development of policies that will promote the continued stable operation of the DNS." Id. Direct influence by the general user population over ICANN decisionmaking, he urged, would threaten stability. See id.

288. ICANN Bylaws Proposal, art. IV, § 4(a)(iv), at http://www.domainhandbook.com/ comp-bylaws2.html (Oct. 2, 1998) (on file with the Duke Law Journal).

289. See Rony, supra note 121, art. II.

290. See Letter from J. Beckwith Burr, Associate Administrator, National Telecommunications and Information Administration, to Herb Schorr, Executive Director, USC Information Sciences Institute (Oct. 20, 1998), http://www.ntia.doc.gov/ntiahome/press/icann102098.htm (on file with the Duke Law Journal). For Magaziner's views, see Sims, supra note 183.

291. Burr, supra note 290. 
In response, ICANN agreed to the election of nine at-large directors by an individual membership. ${ }^{292}$ Its bylaws, as revised, called for the creation of a membership advisory committee to develop recommendations as to how such a membership might be structured. ${ }^{293}$ On its road to creating a membership, the board briefly endorsed what proved to be a hugely unpopular plan under which at-large members would choose members of an "At-Large Council," who would, in turn, choose board members. ${ }^{294}$ Faced with a rebellion at its Cairo meeting, the board backed down and promised that in the fall of 2000, individual ICANN members would directly elect one board member in each of the five geographic regions that, for ICANN geographic diversity purposes, make up the world. ${ }^{295}$ A few months later, at its Yokohama meeting, the board resolved that the five at-large directors elected in 2000 will sit for two years alongside four holdover directors from the initial board. ${ }^{296}$

Under the rules approved in Yokohama, each of the five new directors was to be elected in a single geographical region (North America, Central \& South America, Europe, Africa, and Asia/Pacific) ${ }^{297}$ In each of those regions, candidates for director were to be put forward by an ICANN-appointed nominating committee. ${ }^{298}$ Candidates could be nominated by petition as well, subject to the requirements that no person could be nominated that way without the support of two percent of the registered at-large members in his region; no member could support more than one candidate for nomination; and the total number of candidates in its region (including those named by the nominating committee) could not exceed seven. ${ }^{299}$ If the number of candidates exceeding the two percent threshold plus the number of candidates put forward by the nominating committee ex-

\footnotetext{
292. See Sims, supra note 183; ICANN Bylaws, supra note 190, art. V, §§ 4(iv), 9(c).

293. See ICANN Bylaws, supra note 190, art. VII, § 3(c).

294. See Resolutions Approved by the ICANN Board, at http://www.icann.org/santiago/ santiago-resolutions.htm\#anchor21816 (Aug. 26, 1999) (on file with the Duke Law Journal).

295. See Preliminary Report: Meeting of the ICANN Board in Cairo, at http://www.icann.org/minutes/prelim-report-10mar00.htm\#AtLarge (Mar. 10, 2000) (on file with the Duke Law Journal).

296. See Preliminary Report: Meeting of the ICANN Board in Yokohama, at http://www.icann.org/minutes/prelim-report-16jul00.htm\#BylawsOnMembership (July 16, 2000) (on file with the Duke Law Journal).

297. See id.

298. See ICANN Nominating Committee, at http://www.icann.org/nomcom (July 31, 2000) (on file with the Duke Law Journal).

299. See Preliminary Report: Meeting of the ICANN Board in Yokohama, supra note 296.
} 
ceeded seven, then the number of candidates nominated by petition would be reduced accordingly. ${ }^{300}$

The results of the at-large elections were announced as this Article was going to press. The member-nomination process had added nine candidates to the eighteen put forward by ICANN's nominating committee. ${ }^{301}$ In the North American and European regions, all five of the member-nominated candidates (as well as one of the candidates put forward by the nominating committee) presented perspectives sharply different from those of the current board members, emphasizing concerns including democracy, free speech, and privacy. ${ }^{302}$ The ultimate winners ${ }^{303}$ included, in North America, Karl Auerbach, who campaigned on a platform of "deep, substantial and fundamental reform," ${ }^{304}$ and, in Europe, Andy Mueller-Maguhn, who heads an organization of "netizens and hackers.",305

The fate of the at-large directors, however, is uncertain. ICANN has announced that following the election, it will conduct a "cleansheet" study of whether the board should include at-large directors at all, and if so, how many there should be and how they should be selected. The study will consider options including direct appointment of at-large directors by the board. ${ }^{306}$ When the clean-sheet study is complete, the board will take "whatever actions it deems appropri-

300. See id.

301. The 18 candidates put forward by the nominating committee are listed on At Large Candidates Nominated by the Nominating Committee, at http://www.icann.org/nomcom/ nominations.htm (July 31, 2000) (on file with the Duke Law Journal); the final set of 27, after adding in those who survived the member nomination process, can be found at Regional Nominees, at http://members.icann.org/nominees.html (last visited Sept. 21, 2000) (on file with the Duke Law Journal). For additional information on the member nomination process, see The Internet Corporation for Assigned Names and Numbers . . Not!, at http://www.icannnot.org (last modified Sept. 10, 2000) (on file with the Duke Law Journal).

302. See Cyber-Federalist No. 5: The ICANN Member Nomination Process, Computer Professionals for Social Responsibility, at http://www.cpsr.org/internetdemocracy/cyber-fed/ Number_5.html (Sept. 6, 2000) (on file with the Duke Law Journal).

303. See ICANN and Election.com Announce Results for First Worldwide Online Vote, at http://members.icann.org/news.htm\#results (Oct. 10, 2000) (listing the winners) (on file with the Duke Law Journal) [hereinafter Results].

304. At Large Candidate Page: Karl Auerbach, at http://members.icann.org/cand/16.html (last visited Oct. 15, 2000) (on file with the Duke Law Journal).

305. At Large Candidate Page: Andy Mueller-Maguhn, at http://members.icann.org/ cand/84.html (last visited Oct. 15, 2000) (on file with the Duke Law Journal). The other winners were Nii Quaynor in Africa, Masanobu Katoh in Asia, and Ivan Moura Campos in Latin America. See Results, supra note 303.

306. See Preliminary Report: Meeting of the ICANN Board in Yokohama, supra note 296 (enacting new art. II, $\S 5$ of the bylaws). 
ate." ${ }^{307}$ The new at-large directors, in other words, will take their seats with the uncomfortable understanding that if the remaining board members are unhappy with their performance, they may vote to eliminate their positions. ${ }^{308}$

How should we evaluate ICANN's use of the techniques of representation? Should we conclude that, by virtue of its structure, it reflects the larger Internet community, and that its democratic credentials lend it legitimacy? Any attempt to see ICANN as a representative body must surmount two key hurdles.

First is the question of what it means to "represent" any community as ill-defined as the Internet community. Unless we are to abandon all mechanisms other than one-person-one-vote, any mapping of votes to interests is to some degree arbitrary. ${ }^{309}$ As the failings of the DNSO constituency model demonstrate, it is difficult to devise workable plans assigning votes to functionally defined sectors of the industry and public and even harder to create new institutions to wield those votes. Yet one-person-one-vote is itself problematic in an environment in which voter organization and turnout may be crucial.

Second, ICANN has manifested a fundamental ambivalence as to whether it ought to be a representative, democratically controlled body. ICANN has repeatedly insisted, after all, that its job is a highly technical one, consisting primarily of technical coordination, not political policymaking. ${ }^{310}$ To the extent that ICANN is properly seen as a vehicle of the technical and expert communities for technical, apolitical decisionmaking, elections and political representation are incongruous and counterproductive.

This last issue is nicely illustrated by a recent e-mail message from Andrew McLaughlin, ICANN's Chief Policy Officer, to members of ICANN's Membership Implementation Task Force. ${ }^{311}$

307. ICANN Bylaws, supra note 190, art. II, $\S 5$.

308. Michael Froomkin, Reflections on ICANN Meeting in Yokohama, at http://www.icannwatch.org (July 16, 2000) (on file with the Duke Law Journal).

309. Cf. ELY, supra note 153, at 124 (remarking that once the U.S. Supreme Court decided to monitor state voting systems for fairness, considerations of administrability made any standard other than one-person-one-vote infeasible); Lewis Powell, Carolene Products Revisited, 82 Colum. L. REv. 1087, 1091 (1982) (stating that any understanding of whether the political process is functioning properly must rest on a substantive vision of the results the process should generate).

310. See supra note 182 and accompanying text.

311. E-mail from Andrew McLaughlin, Chief Policy Officer, ICANN, to Members of ICANN's Membership Implementation Task Force (July 23, 2000), Tasty Bits from the Tech- 
McLaughlin discussed recent problems with ICANN's member signup system, which for the previous two weeks had led the system to display a "server down" message nearly all of the time. ${ }^{312}$ McLaughlin explained that the system was receiving substantially more applications than it had been designed to handle. ${ }^{313}$ Even if the applications could be processed by the server, he continued, ICANN's allocated funding for the at-large membership would not cover the associated postage and personnel costs. ${ }^{314}$ It should be seen as sufficient, he suggested, that ICANN was seeking to give would-be applicants a "fair" (rather than a "guaranteed") opportunity to join. ${ }^{315}$ According to McLaughlin, the increase in applications was especially problematic as a result of "quite irresponsibl[e]" media coverage, in China and elsewhere, urging people to register so as to be able to elect an at-large director from their own country. ${ }^{316}$ The result was a host of applications from "people with no understanding of ICANN." 317

There's the rub. If we are to treat ICANN as politically representative, then the desire of members in China or anywhere else for representation of one of their own on the board is not illegitimate. If, on the other hand, ICANN is, indeed, a technical coordination body, performing only sophisticated and apolitical technical functions, then people "with no understanding" may properly be excluded from its governance. This helps explain why ICANN has so often been reluctant to consider at-large elections and has been wary of member nominations: ICANN wears the mantle of democracy only unsteadily. To the extent it sees itself, and wishes to present itself to others, as simply a technical body, then the techniques of representation are out of place. To evaluate that position, we shall need to revisit a question touched on towards the beginning of this Article: is it more appropriate to view ICANN as a technical coordination body or as one engaged in value choice?

nology Front, http://www.tbtf.com/roving_reporter/icann1.html (on file with the Duke Law Journal).

312. See id.; see also MAL Login Errors a Feature, Not a Bug, Tasty Bits from the Technology Front, at http://www.tbtf.com/roving_reporter/icann1.html (Aug. 17, 2000) (explaining that ICANN throttled back its server to accept no more than 5000 registrations per day, so as not to impose too great a burden on staff resources) (on file with the Duke Law Journal).

313. See McLaughlin, supra note 311.

314. See id.

315. See id.

316. See id.

317. Id. 


\section{The Techniques of Consensus}

ICANN typically characterizes its own work as Internet "technical management" or "technical coordination"; $;{ }^{318}$ it thus evokes a long, and wildly successful, Internet engineering tradition. Internet technical standards historically have been set by the Internet Engineering Task Force (IETF) and other bodies in a voluntary, decentralized, consensus-based manner. ${ }^{319}$ The process "bears a surprising resemblance to the low-tech ideal of the New England town meeting.",320 Groups of engineers, programmers, and computer scientists gather to address Internet technical problems; if they can reach rough consensus on a particular solution, and that solution passes review by other groups of engineers, they publish it more broadly. ${ }^{321}$ Once the solution is shown to work and is endorsed by the IETF, it will generally attract a high degree of public acceptance and legitimacy. ${ }^{322}$

This system does not require formal representative mechanisms. In the words of Internet pioneer Dave Clark (describing the IETF): "We reject kings, presidents and voting. We believe in rough consensus and running code." ${ }^{323}$ A standard is adopted if it is supported by consensus and works in practice; the ultimate test of its success is adoption in the market. ${ }^{32}$

ICANN has sought to situate itself firmly within that Internet tradition of consensus-based standards development. In a letter to Representative Bliley of the House Commerce Committee, ICANN's interim chairman ${ }^{325}$ offered reassurance that no legitimacy problem

318. See supra note 169 and accompanying text.

319. See Joseph P. Liu, Legitimacy and Authority in Internet Coordination: A Domain Name Case Study, 74 IND. L.J. 587, 587-88, 595-98 (1999); Joseph Reagle, Why the Internet Is Good: Community Governance That Works Well, Berkman Center for Internet and Society, at http://cyber.law.harvard.edu/people/reagle/regulation-19990326.html (last visited Sept. 21, 2000) (on file with the Duke Law Journal).

320. Liu, supra note 319, at 595.

321. See id. at 587-88, 595-99.

322. See id. at 596-97.

323. Reagle, supra note 319 (quoting comments of Dave Clark at a 1992 IETF meeting).

324. See id. In his discussion, Reagle quotes the World Wide Web Consortium's policy on consensus: "Groups strive to reach consensus in order to provide a single solution acceptable to the market at-large. If a group makes a decision that causes the market to fragment-despite agreement by those participating in the decision-the decision does not reflect a single market and therefore the group has failed to reach true consensus." Id. (quoting World Wide Consortium Press Document, World Wide Web Consortium, at http://www.w3.org/Consortium/Process/ \#Consensus (last visited Sept. 21, 2000) (on file with the Duke Law Journal).

325. ICANN's current chairman is Esther Dyson, who-before she was chosen as an ICANN initial director-was a well-known Internet guru, editing a prominent newsletter, or- 
existed, or could exist, because "ICANN is nothing more than a vehicle or forum for the development and implementation of global consensus on various policy issues related to the DNS." ${ }^{326}$ In other words, under ICANN's bottom-up structure, policies are initially developed in working groups chartered by the supporting organizations and then passed up the line. No action can be taken unless it has won the consensus of the Internet community. ${ }^{327}$

This approach presents yet another answer to the question of legitimacy. ICANN, the argument runs, can only act in ways that reflect the consensus of the Internet community. The community's process of consensus formation is the same as that of ICANN itself, and ICANN's rules prevent it from acting until a consensus has bubbled up. Accordingly, ICANN exercises no real discretion; it is merely a vehicle for the community will. If ICANN is to claim legitimacy on this basis, though, it must be the case that (1) the issues facing ICANN are susceptible of resolution in a consensus-based process; and (2) ICANN's procedures are well-suited to finding that consensus. Neither of those prerequisites seems in fact to be true.

ganizing conferences, speaking and writing about the Internet, and investing in information technology startups. See Network Profile: Esther Dyson, at http://www.thestandard.com/ people/display/0,1157,1372,00.html (last visited Oct. 11, 2000) (on file with the Duke Law Journal).

326. Dyson, supra note 182. See also Letter from Michael Roberts, CEO, ICANN, to Rep. Howard L. Berman, Ranking Member, United States House Subcommittee on Courts and Intellectual Property (Aug. 4, 1999) (arguing that ICANN is confined "to adopting and implementing consensus policies with respect to a very narrow set of responsibilities"), http://www.icann.org/correspondence/roberts-letter-04aug99. htm (on file with the Duke Law Journal); Letter from Esther Dyson, Interim Chairman, ICANN, to J. Beckwith Burr, Associate Administrator (Acting), National Telecommunications and Information Administration (Nov. 6, 1998), National Telecommunications and Information Administration, http://www.ntia.doc.gov/ntiahome/press/ICANN111098.htm ("We have not made... every change suggested by everyone, because ... some are not supported by a consensus of the Internet community...."); Frequently Asked Questions, at http://members.icann.org/faq.htm (last visited Sept. 21, 2000) (on file with the Duke Law Journal):

What does ICANN do? ICANN is involved in the overall technical management of the Internet, including such functions as the definition and supervision of the domain name system and the unique assignment of IP addresses and protocol parameters (such as port numbers). ICANN establishes basic policies for these activities through a consensus-based process ....

327. Interestingly enough, ICANN's bylaws do not explicitly refer to consensus, except in Article VI, $\S 3$, which provides that the structure of the three supporting organizations must reflect community consensus, and in Article VI.B, which describes the DNSO. See ICANN Bylaws, supra note 190, art. VI. ICANN has entered into contracts with NSI and with the various registrars providing that certain ICANN requirements are not binding on those actors unless they are supported by consensus. See Approved Agreements, supra note 140. 
Two key factors have made "rough consensus" a workable approach in the traditional Internet standards context. First, the community of Internet engineers and system administrators has been a relatively small and homogeneous one, bound together by shared values and professional norms, including respect for technical expertise. ${ }^{328}$ Second, the issues addressed in the consensus process have been technical ones, and the question whether a proposed solution works has been capable of resolution via a (relatively) neutral performance metric. ${ }^{329}$

Those factors are not present in the domain name context. The universe of stakeholders there is large and remarkably diverse. They do not share common values or professional norms, and many of the interested parties have strong economic interests in particular outcomes. ${ }^{330}$ Moreover, the questions to be decided largely rest on competing values and competing claims of right: If the name space is to be limited, how is this limited resource to be allocated? Should the ability to register domain names be governed by the first-come-firstserved principle, by trademark rules, or by some other means? Should registries be operated on nonprofit or for-profit bases? How should we think about companies' sunk investments in the status quo? These are political issues, not technical ones, and they cannot be resolved from a pure engineering standpoint, asking which solution works best. They require value choices. ${ }^{331}$

In short, there is no reason to believe that any genuine consensus can be formed around the issues ICANN is addressing. It would be undesirable for ICANN truly to seek consensus before acting, for that would mean that it could do nothing at all.

Further, ICANN does not have procedures that would enable it to recognize consensus (or the lack of consensus) surrounding any given issue. The principal component of ICANN's structure designed to generate recognizable consensus is the development of policy through the supporting organizations. Yet ICANN has not been successful in using the supporting organizations to generate policy on any but the highest degree of generality. ${ }^{332}$ The only supporting organization that has sought to develop policy has been the DNSO, and it is

328. See Liu, supra note 319 , at 598-99.

329. See id.

330. See id. at 611, 614-15.

331. See id. at 604-12.

332. See supra notes $218,258-67$ and accompanying text. 
doubtful that that body is capable of generating consensus in any meaningful way. ${ }^{333}$ The bulk of ICANN's decisions have been made with little supporting organization input. As to those, "[h]ow ICANN interprets 'consensus,' and how it thinks such a consensus is uncovered, is deeply mysterious." ${ }^{334}$

ICANN has commonly taken actions with no clear showing of consensus in the community at large, and its methods of determining that a particular action was supported by consensus have often seemed opaque. One example that comes to mind is ICANN's shortlived declaration that there was a consensus of the Internet community behind its creation of an at-large council to elect at-large board members indirectly, notwithstanding the absence of any visible support for this plan outside of ICANN's own hallways. ${ }^{335}$ Other instances are easy to find. ${ }^{336}$ Indeed, had ICANN truly been bound by a requirement that it not act except in the presence of consensus, it would, in several cases, have been paralyzed. ICANN is proceeding with the deployment of new generic top-level domains, ${ }^{337}$ notwithstanding a notable lack of consensus on any implementation point. Only the desirability of one or more new top-level domains is even close to common ground. ${ }^{338}$

333. See supra notes 249-57 and accompanying text.

334. David Post et al., Elusive Consensus, at http://www.icannwatch.org/archives/essays/ 932565188.shtml (July 21, 1999) (on file with the Duke Law Journal).

335. See supra notes 294-95 and accompanying text.

336. Post et al. note:

On the one hand, [ICANN board members] "do not see a global consensus demanding that ICANN hold all its meetings in public"-probably the one thing, in this whole process, on which it looks to us like there IS global consensus. [Who, besides the Board itself, has argued against full transparency and openness in all Board meetings!] On the other hand, does ICANN really believe that they HAVE achieved a global "consensus" on the other policy issues on which they have taken positionsendorsing portions of the WIPO Report, say, or imposing the $\$ 1$ fee? They cite an "evident consensus" that the Bylaws should be changed to prevent NSI from naming non-NSI opponents to the Names Council-without explaining where exactly they found this consensus. We perceive a great divergence of opinion on these questions ....

Post et al., supra note 334 .

337. As a policy matter, I consider this an unequivocally good thing. See my statement in Position Paper A on New gTLDs, Domain Name Supporting Organization, at http://www.dnso. org/dnso/notes/19991023.NCwgc-report.html\#Position Paper A (Oct. 23, 1999) (on file with the Duke Law Journal).

338. The DNSO chartered a broad-based working group to generate policy recommendations on the deployment of new gTLDs, and that group after nearly a year's work reported back several points on which there was rough consensus within the group. See Report (Part One) of Working Group C of the Domain Name Supporting Organization Internet Corporation for Assigned Names and Numbers, Domain Name Supporting Organization, at http://www.dnso.org/ 
Occasionally, ICANN officers acknowledge that its process falls short of the consensus ideal. Consider, for example, the question of openness. It is uncontroversial that true consensus-based procedures must be open to participation by members of the relevant community. ${ }^{339}$ Yet according to ICANN's CEO, it is "obvious[]" that ICANN can only reconcile its "effective private-sector technical coordination" with the provision of "the maximum access to ICANN consensus processes for the maximum number of people" by means of "difficult tradeoffs." ${ }^{340}$ It appears that the circles within which ICANN seeks consensus are sharply more limited than the set of Internet actors interested in and affected by its policies. Yet once ICANN so limits its catalog of players to be taken seriously, its legitimacy is at best dependent on its justifications for whom it excludes. ${ }^{341}$

Finally, ICANN lacks other characteristics that makes traditional Internet standards development work well. ${ }^{342}$ In traditional Internet standards development, the rule of "running code" requires that before a standard can be adopted, it "must be implemented and tested for correct operation and interoperability by multiple independent parties and utilized in increasingly demanding environments." ${ }^{343} \mathrm{Be}$ cause the successful development of an Internet standard requires "practice and courageous patience" as well as rigorous testing, ${ }^{344}$ engineers tend to be conservative in what they specify. ${ }^{345}$ A too-broad

dnso/notes/20000321.NCwgc-report.html (Mar. 21, 2000) (on file with the Duke Law Journal); Jonathan Weinberg, Two Additional Items and Vote Tallies, Domain Name Supporting Organization, at http://www.dnso.org/clubpublic/council/Arc03/msg00556.html (Apr. 17, 2000) (on file with the Duke Law Journal). The Names Council found that the working group's first point (that new gTLDs should be created) was supported by community consensus, but it found no community consensus supporting the second. It took no action on the rest. See DNSO Names Council Teleconference-Minutes, Domain Name Supporting Organization, at http://www.dnso.org/dnso/notes/20000418.NCtelecon-minutes.html (Apr. 18, 2000) (on file with the Duke Law Journal).

339. See Post et al., supra note 334.

340. Roberts, supra note 195.

341. See David M. Lawrence, Private Exercise of Governmental Power, 61 IND. L.J. 647, 68889 (1986) (concluding that it may be acceptable to delegate public power to a private group that represents all affected interests and acts by consensus, because the legislator can be confident that the group's output will not disadvantage excluded parties).

342. See Reagle, supra note 319, at Appendix 3 (evaluating ICANN in light of traditional Internet policymaking principles in an appendix entitled "Case Study: Why ICANN is Frightening").

343. See S. Bradner, RFC 2026, The Internet Standards Process-Revision 3, § 1.2, at http://www.rfc-editor.org/rfc/rfc2026.txt (Oct. 1996) (on file with the Duke Law Journal).

344. See Reagle, supra note $319, \S 4.4 .2$.

345. See id. § 4.4.1. 
standard will not attract the community support necessary to ensure its deployment and implementation. ${ }^{346}$ This provides protections against mission creep and overly broad results. ${ }^{347}$ ICANN does not share these institutional features. By abandoning any reliance on detailed policy development in the supporting organizations, and placing ever-increasing reliance on notice-and-comment rulemaking conducted by staff, ICANN has helped ensure an efficient policy development process-but it has eliminated checks and balances that might contain its regulatory scope.

The lessons of U.S. administrative law point in the same direction. I suggested earlier that consensus-based Internet policy development bears some similarity to the process of negotiated rulemaking, where publication of a proposed rule depends on the agency's ability to mediate a consensus agreement among interested stakeholders. ${ }^{348}$ Yet in negotiated rulemaking, a key factor powering the drive towards consensus is the desire to create a rule that will not be challenged in court. Any party with standing to file a suit for judicial review has bargaining power, because any such party can destroy the carefully negotiated consensus through litigation. ${ }^{349}$ This helps ensure that politically weaker interests are not simply omitted from the negotiations. It favors a process in which every negotiator is able to extract some concession. Only where the bargaining process can generate a negotiated compromise satisfactory to every participant can a "consensus" rule emerge. ${ }^{350}$ ICANN's process carries no similar guarantees. With no requirement of unanimous agreement and no threat of judicial review, it is easy to ignore or slight the views of politically less-powerful interests. Consensus can be defined as whatever the convenor claims it to be.

Perhaps ICANN's claims of consensus relate instead to a weaker dynamic. Esther Dyson, in her letter to Representative Bliley, urged

346. See id. $\$ 4.4 .2$.

347. See id. $\$$ 4.4.1. Moreover, because implementation of an Internet standard is voluntary, traditional Internet standards organizations do not provide centralized points of control that can be targeted by governments seeking to apply their own policies to the Internet. See id. § 4.1.

348. See Negotiated Rulemaking Act of 1990, 5 U.S.C. $\$ \S 561-70$ (1994); supra note 319. The parallel is imperfect. U.S. negotiated rulemaking requires actual unanimity, not merely rough consensus. See Philip J. Harter, The Political Legitimacy and Judicial Review of Consensual Rules, 32 AM. U. L. REV. 471, 482-83 (1983). The process involves horse-trading by representatives of the various interests in an environment in which the actors can be held to their deals. See Susskind \& McMahon, supra note 181, at 136-37.

349. See Weinberg, supra note 174 , at 632.

350. See Harter, supra note 348 , at $482-83$. 
that ICANN "has no power or authority to impose anything on anyone." ${ }^{351}$ If it "were not reasonably successful as a consensus development vehicle, it would simply disappear; since it relies for its existence on voluntary compliance and cooperation by diverse parties around the world, ICANN cannot survive without broad support throughout the global Internet community. ${ }^{, 352}$

This is an important point: ICANN cannot afford to antagonize powerful actors. It is vulnerable to the actions of governments and those with control over key resources. It cannot easily force root server operators, or the operators of country code top-level domain registries, to cooperate with it; in order to gain that cooperation, it must avoid doing anything they deem seriously wrong. ICANN does not want trademark interests to mobilize in Congress to override its actions; it does not want the Department of Commerce to withhold needed support. Especially now, when it is still casting around for reliable funding sources, it cannot afford to antagonize any entity likely to give it money. In the words of ICANN CEO Michael Roberts:

Railing away at ICANN because it doesn't meet some ideal model of democracy is likely to be about as effective as complaining that the US Congress is too dominated by the money of those who finance political campaigns. Everyone knows that, the question is how do you work from within the system to balance competing interests, many of which possess economic power. ${ }^{353}$

ICANN has strong incentives not to take any action that will seriously antagonize an important DNS player. Important players, in this context, include the proprietors of key resources, the U.S. government, players with substantial influence with the U.S. government, and players who may provide important income streams. This constraint, more than anything else, is the real limitation on ICANN's freedom of action. Should one view this as a meaningful form of consensus? Is it sufficient to solve the "problem of discretion?"

To ask this question, unfortunately, is to answer it. This constraint is unlike true consensus in at least two crucial respects. First, it is skewed. Economic and political influence do not translate into substantively correct positions. The relative political power of, say, the

\footnotetext{
351. Dyson, supra note 182.

352. Id.

353. Comments on the Civil Society Statement, Computer Professionals for Social Responsibility, at http://www.cpsr.org/internetdemocracy/Statement_July-13_Comments.html (July 30, 2000) (on file with the Duke Law Journal).
} 
American Intellectual Property Law Association and the International Trademark Association on the one hand, and domain name registrants without trademarks on the other, does not say anything about which has a better public-policy case. ${ }^{354}$ That ICANN has incentives to favor more powerful over less powerful actors may be realpolitik, but it does not generate any confidence that ICANN is making the right choices. Second, this constraint is not very constraining. The need not to antagonize important players defines a range of unacceptable outcomes, but ICANN has freedom of movement within a range of politically tolerable ones. Within that range, ICANN staff (whose recommendations are generally adopted at the board's public meetings $)^{355}$ can pursue their vision of the true, good, and convenient, and label it "consensus." That result does not reflect genuine consensus of the Internet community, or political representation, or the role of technical expertise. It is only as good as the judgment and instincts of the mostly non-technical ${ }^{356}$ ICANN staff.

\section{CONCLUSION}

ICANN cannot accomplish its goals without the cooperation of other Internet actors, and that cooperation will not be forthcoming unless the Internet community sees its claim to supervise the domain name system as legitimate. ICANN's task, in seeking to convince the Internet community of its legitimacy, is complicated by the fact that it is a private entity playing the sort of role more commonly played in our society by public entities. ICANN is currently addressing issues including how many top-level domains should exist, to whom they should be allotted, what the economic structure of registration in those domains should be, what content controls-if any-should be imposed on registrants in those domains, what special rights trademark owners should have, and what privacy claims domain name registrants should be able to assert. In short, it is making important public policy decisions, and it is implementing some of its choices via means that look uncannily like command-and-control regulation. If ICANN is to establish its legitimacy, it must be able to answer the charge that this exercise of authority is inconsistent with our ordinary understandings about public power and public policymaking.

354. The U.S. administrative agency, of course, is vulnerable to the same critique.

355. See, e.g., Minutes, at http://www.icann.org/minutes/minutes-10mar00.htm (Mar. 10, 2000) (on file with the Duke Law Journal).

356. See supra note 172. 
Some of the legitimacy questions ICANN faces are similar to those historically faced by the U.S. administrative agency. To be sure, the federal agency has answers to its legitimacy challenges that ICANN cannot provide. The agency can point to a grant of power in a statute enacted by the U.S. Congress and to administrators nominated by the President and confirmed by the Senate. Nonetheless, the federal agency throughout history also faced legitimacy objections. Agencies have no direct political accountability, and yet they often appear to have tremendously broad policy autonomy. More than anything else, administrative law represents an attempt to reconcile broad agency policymaking discretion with the agency's insulation from democratic control.

In developing structures, procedures, and rhetoric to establish its own legitimacy, ICANN has drawn on techniques that parallel the crucial philosophical justifications for the legitimacy of the unelected federal administrative agency. First, it has invoked what one might call the techniques of administrative law: it has, in important respect, structured itself so that it looks like a classic U.S. administrative agency, using, and purportedly bound by, the tools of bureaucratic rationality. Second, it has invoked the techniques of representation: it has adopted structures and procedures that make it resemble a representative (that is to say, elective) government body. Finally, it has invoked the techniques of consensus: it has asserted that its structure and rules ensure that it can only act in ways that reflect the consensus of the Internet community.

None of these responses, though, seem satisfactory. The techniques of administrative law are inadequate in this context, for they do not provide meaningful constraint in the absence of judicial review. In the administrative agency context, it is judicial review for rationality and statutory faithfulness that drives the agency's own commitment to process and rationality. But there is no ICANN institution that performs the function that judicial review performs for administrative agencies. Absent such an institution, ICANN cannot make the claim that the values of the traditional administrative law model-bureaucratic rationality and procedural regularity-will control its discretionary power, and there is nothing to confine ICANN within any particular sphere of authority.

The techniques of representation seem more promising. Yet representation is hardly straightforward: the current Domain Names Supporting Organization provides a good example of how not to structure a representative body. There may be no way to craft an elec- 
tive mechanism that ensures that the immensely heterogeneous Internet community is represented, in any real sense, within ICANN's structure. Indeed, any such mechanism presents the potential for distortions and capture. Further, we can expect those who are wellrepresented by the current board structure to oppose adjustments that dilute their influence. Only the lame-duck nature of the initial board, ICANN's quest for legitimacy, and Department of Commerce oversight have allowed us to get as far as we have gotten.

The election of new at-large directors, as this Article goes to press, including candidates who campaigned on platforms of skepticism and reform, is tremendously heartening. These new directors can bring to the board badly needed perspectives. This election has lent a voice to the class of ordinary users, who previously had minimal input into ICANN, and it may cause a broader range of the Internet public to feel that there is someone looking out for their interests within the ICANN structure. Although elections can broaden the set of communities given a voice within ICANN's halls, they cannot render ICANN into a reflection of the Internet community. They can improve ICANN's decisionmaking, but they cannot reliably aggregate the preferences of the Internet world at large, and thus tell ICANN whether to adopt a disputed policy.

Nor will the techniques of consensus do the job. ICANN does not have procedures that would enable it to recognize consensus, or the lack of consensus, surrounding any given issue. It has commonly taken actions with no clear showing of consensus in the community at large, and its methods of determining that a particular action is supported by consensus have often seemed opaque. Indeed, there is no reason to believe that the issues over which ICANN seeks to exercise authority are ones around which any genuine consensus can be formed. For ICANN, "consensus" has often seemed to mean simply that the organization is disinclined to antagonize important DNS actors. That limitation, however, is both skewed and insufficiently constraining.

In sum, none of the three techniques I have discussed-the techniques of administrative law, representation, and consensus-can deliver ICANN legitimacy. So what is ICANN to do? I have only this modest suggestion: if ICANN cannot gain acceptance through rhetoric, internal structure, and procedural devices, it may be able to do so through its substantive choices. ICANN grew out of the desire of Jon Postel and other Internet luminaries, starting in 1996, to expand the name space and create competition in domain name registration. It 
was that goal that spurred the formation of IAHC and led to the White Paper. ICANN should focus on that central mission. It should do what it was designed to do, and as little as possible else. Beyond the addition of new top-level domains, in other words, ICANN should seek to chart the narrowest course possible, minimizing the scope of its policy determinations. If ICANN appears serious about minimizing its sphere of authority, then its discretion will seem less threatening. Such an approach would make ICANN look more like IANA, which was loathe to enter into policy thickets removed from its core domain name and IP address responsibilities. ${ }^{357}$

This means that ICANN should resist the temptation to put infrastructure in place designed to advance particular constituencies' visions of a commercially hospitable Internet. It should not adopt policies that seem designed to further the interests of those segments of the business community that are closest to it. It should resist the temptation to raise the comfort level of trademark proponents by building new trademark protection mechanisms into the DNS. It should not load down the selection process for new top-level domain registries with extensive inquiries as to which application would best serve the public interest as ICANN sees it.

ICANN is currently exercising far-reaching policy discretion. Yet none of the paths it has explored lead to meaningful accountability. ICANN should by all means pursue procedural regularity, select its board members through representative elections, and seek to divine community consensus where it can be found. Beyond all of these, though, if it is to be viewed as legitimate, it needs to display the humility, openness, and restraint it so far has lacked.

357. See, e.g., Postel, supra note 42 (explaining that IANA would rely on the ISO 3166 list in designating country code top-level domain names because "[ $\mathrm{t}$ ] he IANA is not in the business of deciding what is and what is not a country"). 